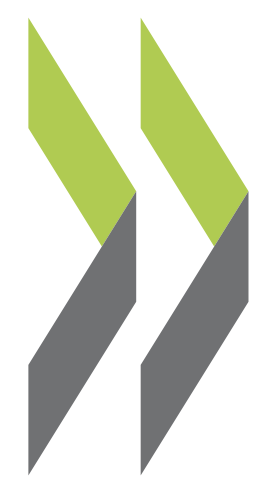

OECD Economics Department Working Papers No. 1507

\title{
Cyclical vs structural effects on health care expenditure trends in OECD countries
}

Luca Lorenzoni, Jonathan Millar, Franco Sassi, Douglas Sutherland 
CYCLICAL VS STRUCTURAL EFFECTS ON HEALTH CARE EXPENDITURE TRENDS IN OECD COUNTRIES

ECONOMICS DEPARTMENT WORKING PAPERS No. 1507

\section{By Luca Lorenzoni, Jonathan Millar, Franco Sassi, and Douglas Sutherland}

OECD Working Papers should not be reported as representing the official views of the OECD or of its member countries. The opinions expressed and arguments employed are those of the author(s).

Authorised for publication by Isabelle Koske, Deputy Director, Country Studies Branch, Economics Department.

All Economics Department Working Papers are available at www.oecd.org/eco/workingpapers.

JT03435605 
OECD Working Papers should not be reported as representing the official views of the OECD or of its member countries. The opinions expressed and arguments employed are those of the author(s).

Working Papers describe preliminary results or research in progress by the author(s) and are published to stimulate discussion on a broad range of issues on which the OECD works.

Comments on Working Papers are welcomed, and may be sent to OECD Economics Department, 2 rue André Pascal, 75775 Paris Cedex 16, France, or by e-mail to eco.contact@oecd.org.

All Economics Department Working Papers are available at www.oecd.org/eco/workingpapers.

This document and any map included herein are without prejudice to the status of or sovereignty over any territory, to the delimitation of international frontiers and boundaries and to the name of any territory, city or area.

The statistical data for Israel are supplied by and under the responsibility of the relevant Israeli authorities. The use of such data by the OECD is without prejudice to the status of the Golan Heights, East Jerusalem and Israeli settlements in the West Bank under the terms of international law.

On 3 May 2018, the OECD Council invited Lithuania to become a Member. At the time of preparation the deposit of Lithuania's instrument of accession to the OECD Convention was pending and therefore Lithuania does not appear in the list of OECD Members and is not included in the OECD zone aggregates.

On 25 May 2018, the OECD Council invited Colombia to become a Member. At the time of preparation the deposit of Colombia's instrument of accession to the OECD Convention was pending and therefore Colombia does not appear in the list of OECD Members and is not included in the OECD zone aggregates.

\section{(c) OECD (2018)}

You can copy, download or print OECD content for your own use, and you can include excerpts from OECD publications, databases and multimedia products in your own documents, presentations, blogs, websites and teaching materials, provided that suitable acknowledgment of OECD as source and copyright owner is given. All requests for commercial use and translation rights should be submitted to rights@oecd.org 


\section{Abstract / Résumé \\ Cyclical vs structural effects on health care expenditure trends in OECD countries}

Health care expenditure per person, after accounting for changes in overall price levels, began to slow in many OECD countries in the early-to-mid 2000s, well before the economic and fiscal crisis. Using available estimates from the OECD's System of Health Accounts (SHA) database, we explore common trends in health care expenditure since 1996 in a set of 22 OECD countries. We assess the extent to which the trends observed are the results of cyclical economic influences, and the respective contributions of changes in relative prices, health care volumes and coverage to the slowdown in health care expenditure growth. Our analysis suggests that cyclical factors may account for a little less than one half of the estimated slowdown in health care spending since the crisis, suggesting that structural changes have contributed to the trends. Before the crisis the slowdown in health care expenditure growth was accounted for by health care prices growing less than general prices and a reduction in care volumes, whereas the latter accounts for most of the steeper deceleration after the crisis. Although both privately and publically financed health care expenditure grew at a reduced pace during the study period, the sharp post-crisis deceleration happened mostly in the public component. When examined by function, the slowdown in publicly-financed expenditure has been largest in curative and rehabilitative care (particularly after the crisis) and in medical goods (especially pharmaceuticals), whereas the deceleration in the privately financed component is largely in medical goods (including pharmaceuticals). We conclude that structural changes in publicly financed health care have constrained the growth of care volumes (especially) and prices leading to a marked reduction in health care expenditure growth rates, beyond what could be expected based on cyclical economic fluctuations. We examine a range of government policies enacted in a selection of OECD countries that likely contributed to the structural changes observed in our analysis.

This Working Paper relates to the 2016 OECD Economic Survey of the United States.

JEL Codes: C23, H51, I18

Keywords: Health; prices; government expenditures

$* * * * * * * * * * * * * * * * * * * * * * * * * * * *$

\section{Effets sur les tendances des dépenses de santé dans les pays de l'OCDE : sont-ils conjoncturels ou structurels ?}

Les dépenses de santé par habitant, après avoir pris en compte les changements des niveaux de prix de l'ensemble de l'économie, ont commencé à ralentir dans la plupart des pays de l'OCDE dès 2000-2005 bien avant le déclenchement de la crise économique et fiscale. À partir des données disponibles dans la base de données sur les comptes de la santé, nous analysons les évolutions communes dans les dépenses de santé à partir de 1996 dans 22 pays de l'OCDE. Nous évaluons dans quelle mesure les évolutions observées sont les résultats d'influences économiques conjoncturelles et les contributions respectives à ce ralentissement des variations du niveau des prix spécifique de la santé par rapport celui de l'ensemble de l'économie, du volume des services de santé et de la couverture de la population. Notre analyse suggère que les facteurs conjoncturels expliquent un peu moins de la moitié de la décélération de la croissance des dépenses depuis la crise indiquant que les changements structurels ont contribué aussi largement à ce ralentissement. Avant la crise, le ralentissement de la croissance des dépenses de santé 
s'expliquait par une augmentation des prix spécifiques de la santé moindre que celle des prix de l'ensemble de l'économie et par une réduction des volumes des services de santé, ce dernier facteur expliquant la majeure partie du ralentissement après la crise. Bien que les dépenses de santé tant publiques que privées aient ralenti pendant le période analysée, le ralentissement après la crise a été surtout observé dans le secteur public. Quand on analyse l'évolution par fonction, le ralentissement des dépenses publiques de santé a été particulièrement important pour les soins curatifs et de réadaptation (surtout après la crise) et pour les biens médicaux (produits pharmaceutiques principalement), tandis que le ralentissement dans les dépenses privées s'observe surtout pour les biens médicaux (y compris les produits pharmaceutiques). Nous concluons que les changements structurels dans les dépenses de santé financées par le secteur public ont freiné la croissance des volumes des soins de santé (en particulier) et des prix, ce qui a entraîné une réduction marquée des taux de croissance des dépenses de santé, au-delà de ce que l'on pouvait attendre sur la base des fluctuations économiques conjoncturelles. Nous examinons une série de politiques gouvernementales adoptées dans une sélection de pays de l'OCDE qui ont probablement contribué aux changements structurels observés dans notre analyse.

Ce document de travail se rapporte à l'Étude économique des États-Unis 2016.

JEL Codes: C23, H51, I18

Mots clés : Santé; prix; dépenses gouvernementales 


\section{Table of contents}

1. Cyclical versus structural effects on health care expenditure trends in OECD countries........... 7

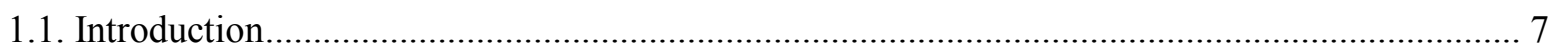

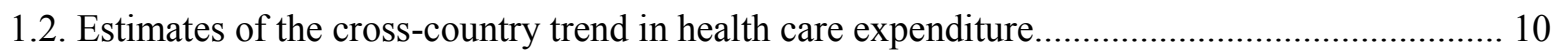

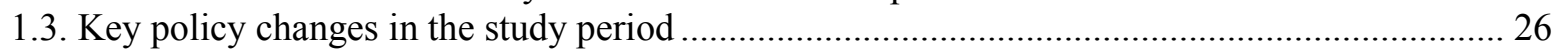

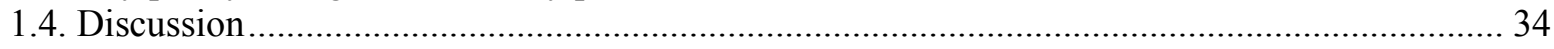

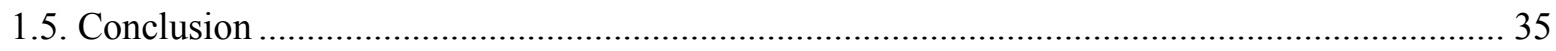

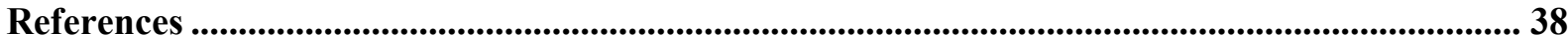

\section{Tables}

Table 1. Robustness of estimated cyclical parameters to alternative specifications ............................. 36

\section{Figures}

Figure 1. Health care expenditure has decelerated

Figure 2. Relative price and care volumes have decelerated after the 2008 economic and fiscal crisis

Figure 3. Contribution to the cross-country health care expenditure slowdown by source of funding. 16

Figure 4. Cyclical influences explain only some of the cross-country slowdown in health care expenditure

Figure 5. Contribution to the cross-country health care expenditure slowdown by functional expenditure category

Figure 6. Contribution to the cross-country health care expenditure slowdown by selected functional expenditure sub-categories.

Figure 7. Contribution to the cross-country publicly financed health care expenditure slowdown by functional expenditure sub-categories

Figure 8. Contribution to the cross-country privately financed health care expenditure slowdown by functional expenditure categories.

Figure 9. Per capita pharmaceutical expenditure (in real terms at 2005 US\$ Purchasing Power Parities) trends across selected OECD countries, 1996 - 2013.

Figure 10. Per capita hospital expenditure (in real terms at 2005 US\$ Purchasing Power Parities)

trends across selected OECD countries, 2004 - 2013

\section{Boxes}

Box 1. Background on comparison of health care spending across OECD high-spending countries ... 37 


\title{
1. Cyclical versus structural effects on health care expenditure trends in OECD countries
}

\author{
By Luca Lorenzoni, Jonathan Millar, Franco Sassi and Douglas Sutherland ${ }^{1}$
}

\subsection{Introduction}

1. This paper explores common trends in the growth rate of health care expenditure since 1996 in a set of 22 countries of the Organisation for Economic Co-operation and Development (OECD). ${ }^{2}$ Available data show that health care expenditure per personreckoned in terms of the overall price level - began to slow in many OECD countries well before the economic and fiscal crisis in the early-to-mid 2000s (Figure 1). The experience of the United States (US) is in many ways representative of these broader trends, with health care expenditure decelerating rapidly from comparatively high rates around 2002 (indeed, to rates below many comparator countries), then after the economic and fiscal crisis of 2008-09 settling at average growth rates about half the average leading-up to the recession. However, preliminary analysis of the available 2014 data suggests that health care expenditure growth have rebounded in the US primarily following coverage expansions under the Affordable Care Act and new specialty medications such as those used to treat hepatitis C (Martin et al 2016; Martin et al 2017), and to a lesser extent in other comparator countries.

1 L. Lorenzoni and Franco Sassi are with the OECD Directorate for Employment, Labour and Social Affairs, Health Division; Jonathan Millar and Douglas Sutherland are with the OECD Economics Department. This paper has also been released as OECD Health Department Working Paper No. 92. 
Figure 1. Health care expenditure has decelerated

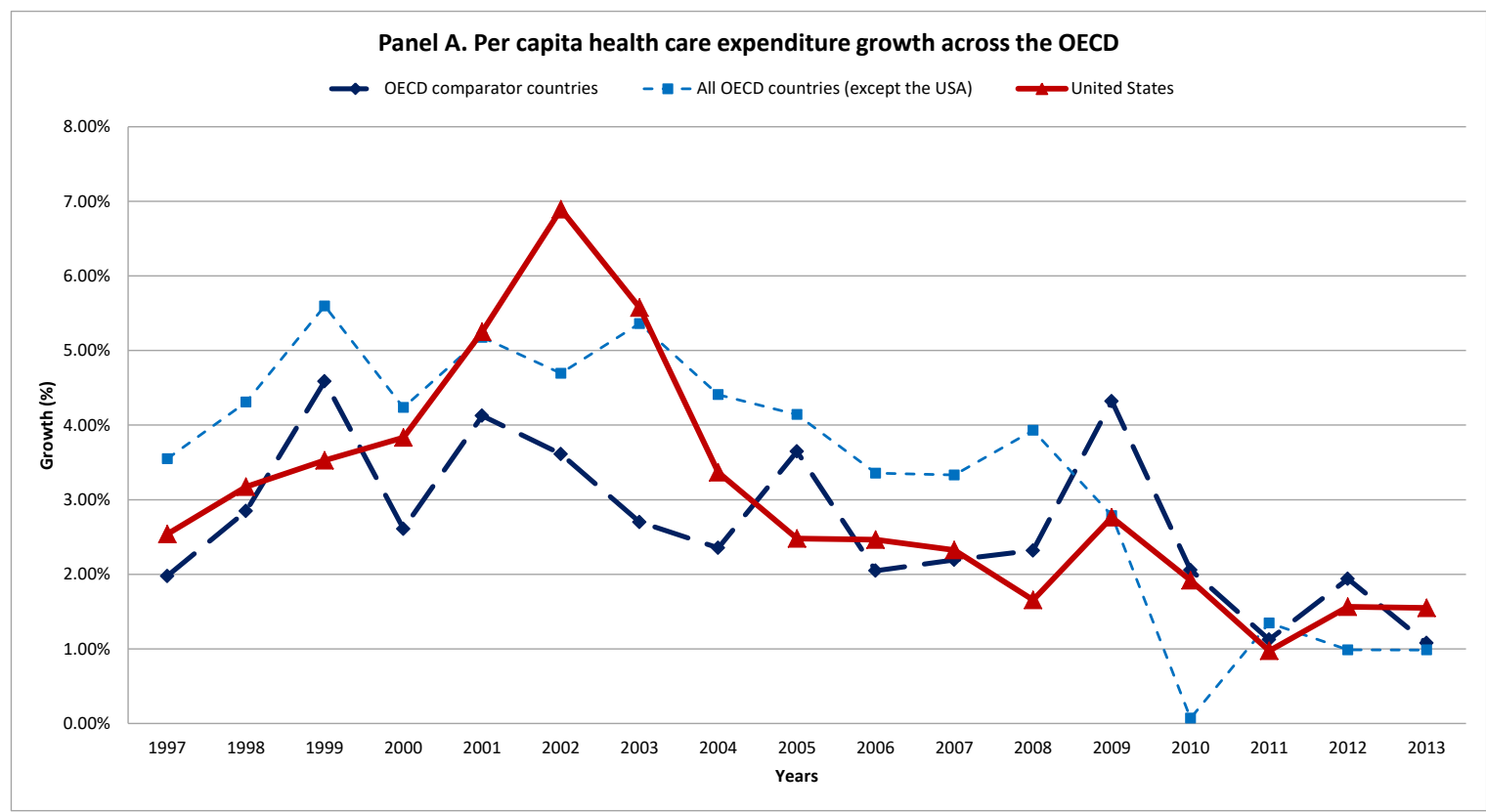

OECD comparator countries: Canada, Denmark, France, Germany, Japan, the Netherlands and Switzerland

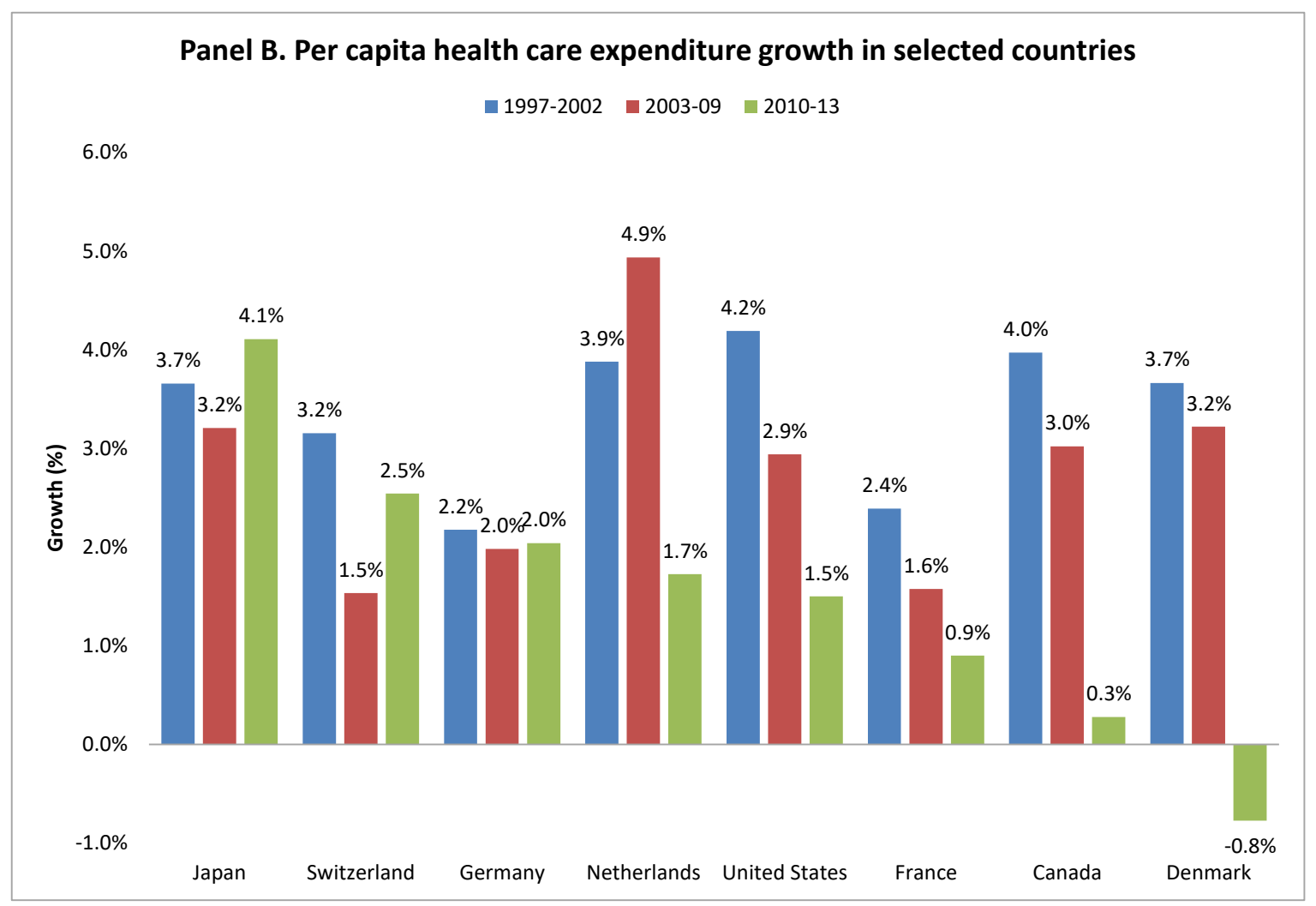

Source: OECD Health Statistics 2016 
2. The analysis uses expenditure data from the OECD's System of Health Accounts (SHA) (OECD, Eurostat and WHO, 2011) database. This database provides a systematic account of overall financial flows through national health systems, including information on where money comes from, who manages it, and how it is used. The 2015 release of SHA used in this study includes national expenditure estimates through 2013. These data were complemented with aggregate estimates from national sources and other publications. For the purpose of making comparisons over time, we adjust for inflation on the basis of various aggregate price indexes (Morgan and Astolfi 2013), including proxies for the overall price level specific to each country's health sector.

3. Insights into the causes of the deceleration in health care expenditure growth can be gauged by decomposing spending growth into the annual contribution to overall growth from (i) volumes of health care consumed per insured person, (ii) the price of health care relative to the overall consumption deflator, and (iii) the proportion of the population covered by insurance. Additional insights can be gleaned from examining the contribution of different expenditure categories to aggregate expenditure.

4. Health care expenditure is also affected by cyclical fluctuations of the economy, as expenditure and production typically expand and contract, respectively, during periods of growth and recession. Disentangling the effects of the economic cycle from those produced by policies and other structural factors is challenging, and it is especially so when focusing on individual countries, as idiosyncratic factors may play a large role at that level. Examining common trends in expenditure across many countries may help separate the roles of cyclical effects and policy measures.

5. Special attention is paid to trends in the eight OECD countries with the highest health care expenditure in proportion to gross domestic product (GDP) - Canada, Denmark, France, Germany, Japan, the Netherlands, Switzerland, and the United States (hereafter, the "high-spending countries"). Previous research by Lorenzoni et al. (2014) has shown that real per-capita health care expenditure have decelerated noticeably in a subset of these high-spending countries (Canada, France, Germany, the Netherlands, Switzerland, and the US) since the 2008 economic and fiscal crisis.

6. Health-care systems vary widely across countries in terms of how insurance coverage is organised, health-care is regulated, and by how payments are made to health care providers. Even within the high-spending group, health care coverage is residencebased and mainly financed from taxes in Canada and Denmark, while in the other countries entitlement to health care coverage is contributory. In France and Japan, people cannot choose their insurer, with affiliation to a specific fund determined by professional occupation and/or place of residence, while people can choose their insurer in Germany, the Netherlands and Switzerland. In the United States, health insurance only became mandatory for all United States citizens and legal residents starting in January 2014. Moreover, the financial penalties intended to enforce mandatory insurance in the US were phased in over a three-year period starting in 2014 and are scheduled to increase substantially in 2016 (Rae et al 2015). While these diverse structures present challenges in making cross-country comparisons, these variations also allow scope to examine how the characteristics of different systems affect how expenditure responds to economic fluctuations and policy changes.

7. This paper is structured as follows. First, econometric analysis is used to explore common trends in the growth rate of health care expenditure across a set of OECD countries. Then we discuss shared elements of national health policies that have contributed substantially to this trend. A final section discusses the results. 


\subsection{Estimates of the cross-country trend in health care expenditure}

8. This section uses econometric analysis on panel data for 22 OECD countries to assess whether the slowdown in health care expenditure is indeed broad based, and associated with common features. We assess whether cyclical influences have played in a role in the recent deceleration in health care expenditure, and determine contributions to the slowdown from relative prices, care volumes, and health care coverage.

9. The rest of this section is structured as follows. First, the empirical approach is described, followed by a discussion of how we constructed our panel dataset. We then present results from the baseline estimations. To gain further insight into the sources of the common trend, we perform a decomposition of the common trend in per-capita expenditure growth into contributions by different sources of financing. We then analyse how the year effects in the decomposition interact with measures of aggregate slack $^{3}$. In a final section, the findings of a decomposition of the common trend in per-capita expenditure growth into contributions by detailed expenditure categories by different sources of financing are reported.

\subsubsection{Empirical approach}

10. Our empirical approach permits a decomposition of overall effects on per-capita health care expenditure into components for relative prices, care volumes, and coverage. To do this, we use our panel to estimate separate equations for a set of dependent variables that sum to overall real per-capita expenditures, each with an identical set of controls. Specifically, let $E_{t}^{H}$ represent real health care expenditure per person, which can be decomposed into separate components for the relative price of health care, volumes per covered person, and proportion of the overall population covered as follows:

$$
E_{t}^{H} \equiv P_{t} \cdot H_{t} \cdot C_{t}
$$

where $P_{t}$ denotes the relative price of health care (in terms of the consumption price deflator), $H_{t}$ denotes the volume of health care per covered person, and $C_{t}$ is the rate of health care coverage. Letting lowercase variables represent logs, we posit that overall expenditures are explained by a vector of exogenous variables $X_{t}$, so that

$$
e_{t}^{H}=b^{e} \cdot x_{t}+v_{t}^{e}
$$

where $b^{e}$ is a vector of parameters and $v_{t}^{e}$ is a residual term that assumed to be orthogonal to the set of variables $X_{t}$. Likewise, each component of expenditures can be expressed as:

3. The amount of slack in the economy is essentially a measure of the amount of unused capacity. It represents the quantity of labour and capital that could be employed productively, but isn't; instead, it is idle. More formally, it is defined as the difference between the economy's productive capacity - the amount of goods and services that could be produced if all labour and capital were fully and efficiently employed - and the actual level of economic output. 


$$
\begin{aligned}
& p_{t}=b^{h} \cdot x_{t}+v_{t}^{h} \\
& h_{t}=b^{p} \cdot x_{t}+v_{t}^{p} \\
& c_{t}=b^{c} \cdot x_{t}+c
\end{aligned}
$$

where $v_{t}^{h}$ and $v_{t}^{p}$ are residual terms also assumed orthogonal to Xt. Since $e_{t}^{H}=p_{t}+h_{t}+$ $c_{t}$ and the set of explanatory variables are identical, orthogonality conditions imply that:

$$
\begin{gathered}
b^{e}=b^{p}+b^{h}+b^{c} \\
v_{t}^{e}=v_{t}^{p}+v_{t}^{h}+v_{t}^{c}
\end{gathered}
$$

11. Following this logic, the overall response of per-capita health care expenditure to a given explanatory variable can be deconstructed into responses from prices, volumes, and coverage. Moreover, since the set of explanatory variables is the same in all of these regressions, there is no need to use seemingly unrelated regression techniques to improve the efficiency of the estimator. These latter observations might be particularly valuable in a case where the price and volumes components of expenditures are difficult to disentangle. Specifically, denote measured prices and care volumes by $\breve{h}_{t}^{H}$ and $\check{p}_{t}^{H}$, such that:

$$
\begin{aligned}
& \check{\boldsymbol{h}}_{t}^{H}=\boldsymbol{h}_{t}^{H}+\boldsymbol{u}_{t}^{h} \\
& \check{\boldsymbol{p}}_{t}^{H}=\boldsymbol{p}_{t}^{H}+\boldsymbol{u}_{t}^{p}
\end{aligned}
$$

where $u_{t}^{h}$ and $u_{t}^{p}$ are classical measurement errors that are orthogonal to the explanatory variables $x t$ but need not be mutually orthogonal. Assuming that these measurement errors are unrelated to any measurement errors for health care expenditure or coverage rates, we know that $u_{t}^{h}=-u_{t}^{p}$. Hence, even though the residuals from these two equations will include negatively correlated components when we estimate the system using measured values of $\breve{h}_{t}^{H}$ and $\check{p}_{t}^{H}$ as proxies for their true values, the measurement error would be neither a source of inconsistency nor inefficiency.

\subsubsection{Data}

12. The panel is mostly constructed using the OECD's SHA database. Specifically, we draw estimates for each country of total nominal current health care outlays, outlays by detailed functional categories, and estimates of the portion financed privately and by government. The main functional categories are:

- Curative and rehabilitative care, which can be broken into subcategories for inpatient care, outpatient care, day cases, and home care

- Long-term nursing care, which includes subcategories for inpatient care, home care, and day cases 
- Personal ancillary services, which includes subcategories for clinical laboratory, diagnostic imaging, patient transportation and emergency rescue, and "other"

- Personal medical goods, which can be broken into subcategories for pharmaceuticals and other non-durables and therapeutic devices and other durables; the pharmaceuticals and other non-durables category can be decomposed further into over-the-counter medications, prescribed medicines, and other nondurables

- Collective prevention and public, which includes public and private expenditure on prevention and public health that are not allocated to particular individuals

- Collective administration and insurance, which includes public and private expenditure on insurance and administration costs that cannot be allocated to particular individuals

as well as a seventh "residual" category which includes expenditures that statistical authorities were unable to allocate to the above categories.

13. In addition to these expenditure data from the SHA, we use separate datasets from the OECD and national sources to assemble estimates on the following:

- Measures of population and health care coverage from the OECD health database and country-specific sources,

- Data from the OECD's national accounts databases for the Actual Individual Consumption (AIC) deflator, which includes private personal consumption expenditures as well as government expenditures on goods and services that are allocated in kind to individuals (including most government-provided health care).

- Data from the OECD's national accounts database on the price deflators for government expenditure and for the health services component of personal consumer expenditure.

- Annual measures of both the unemployment gap and the output gap for each country from OECD's Economic Outlook (OECD 2015a).

\subsubsection{Choice of deflator}

14. A particularly important issue for our analysis is the construction of the deflator to convert nominal overall health care expenditure into volumes of health care goods and services, and to construct the relative price of health care goods and services (Dunn et al 2016). The deflator for overall consumer expenditure is not appropriate for this purpose because it includes all consumer goods and services, which likely differ in price from health care goods and services. Productivity growth in the health care sector is often thought to be slower than in most other industries, in part because much of these expenditures are services. For this reason, the price of health care tends to increase over time in relation to other consumer products - a phenomenon often referred to as the cost disease (Baumol, 1967). For this reason, even a broader "AIC" deflator that includes inkind government health care expenditure will tend to understate price increases in health 
care. In turn, deflating nominal expenditures by such a deflator will tend to overstate increases in the volume of health care consumed.

15. To help fix this problem, we construct a proxy for the overall health care deflator by chain aggregating separate proxies for its private and public components. The proxy for the private health care deflator is formed using the deflator for health services consumption, which - although imperfect - at least aligns with the current standards set by national statistical authorities in measuring health care price dynamics. By comparison, prices paid by governments for health care are often tightly regulated by the same governments, so we proxy for these prices using the overall government expenditure deflator for each country ${ }^{4}$. To measure the relative prices of health care goods and services, we divide our proxy for the health care deflator by the AIC deflator. Likewise, we form our measure of real health care expenditure per capita (henceforth, "real expenditure") by dividing overall per-capita health care expenditure by the AIC deflator, so that this variable can be interpreted as the opportunity cost of this expenditure in terms of foregone consumption per person.

\subsubsection{Data cleaning and construction}

16. The detailed SHA expenditure estimates for individual countries have identifiable shortcomings that we address based on assumptions. One such problem is missing data. Whenever possible, we impute data in missing fields using logical identities, such as the requirement that the overall total for a given category must be the sum of its subcomponents. In some countries, we find sudden shifts in the composition of expenditure between different detailed categories, perhaps driven by changes in measurement practices. When we identify such shifts in a given year (defined as expenditure growth in a given detailed category being more than 2.5 standard deviations from its sample mean), we null out all of the detailed expenditure estimates preceding the change. Detailed expenditure estimates by function are also nulled out in cases where the residual ("unallocated") category accounted for more than 25 percent of the overall total, and in cases where the measured sum of expenditures across all categories fell short of the overall total by more than 5 percent. We also discard all of the expenditure data for one country (Sweden) that experienced in a very sizeable jump (23 percent) in its overall real 2011 expenditure estimate that was hard to reconcile.

17. After excluding countries with incomplete data, our panel includes 22 countriesAustria, Belgium, Canada, Czech Republic, Germany, Denmark, Finland, France, Hungary, Iceland, Israel, Italy, Japan, Republic of Korea, the Netherlands, Norway, New Zealand, Portugal, Slovenia, Switzerland, United Kingdom and the United States. For each of these countries, we have a balanced panel of overall annual health care expenditure for the 18 years from 1996 to 2013, for a total of 396 observations. Of these, detailed data on expenditure by function are available for 248 observations, with the detail missing mostly from New Zealand, Switzerland, Italy, United Kingdom and Korea. By financing type, we can break down overall expenditures for a total of 374 observations, with the missing observations entirely from United Kingdom.

4. We recognise that some countries have a special deflator for public health care expenditure that exceeds the deflator of overall government expenses. 


\subsubsection{Results}

18. We start by constructing a cross-country time trend in health care expenditure and a breakdown of contributions to this trend from care volumes, relative prices, and coverage. To accomplish this, we project contributions to each country's per-capita real health care expenditure growth from these three components on separate time dummies from 1996 to 2013, along with separate controls for country fixed effects. Figure 2 shows a time plot of contributions to the time effects for overall expenditure from each of these three components. A deceleration in overall expenditures - the sum of the three barstook hold in the early-2000s and then intensified in the aftermath of the economic and fiscal crisis in 2008 and 2009. The gradual deceleration in the period leading up to the crisis was about evenly reflecting in slowing contributions from the volumes of health care consumed and relative health care prices, whereas the sharp post-crisis deceleration in overall expenditure was mainly reflected in care volumes. Coverage played essentially no role in the cross-country trend in health care expenditure growth. The slowdown in overall expenditure since the early-2000s would be smoother if not for the collapse of energy prices during the crisis, which led to a temporary jump in the rate of increase in of health care prices (relative to a consumption bundle that includes energy goods and services) in 2009.

Figure 2. Relative price and care volumes have decelerated after the 2008 economic and fiscal crisis

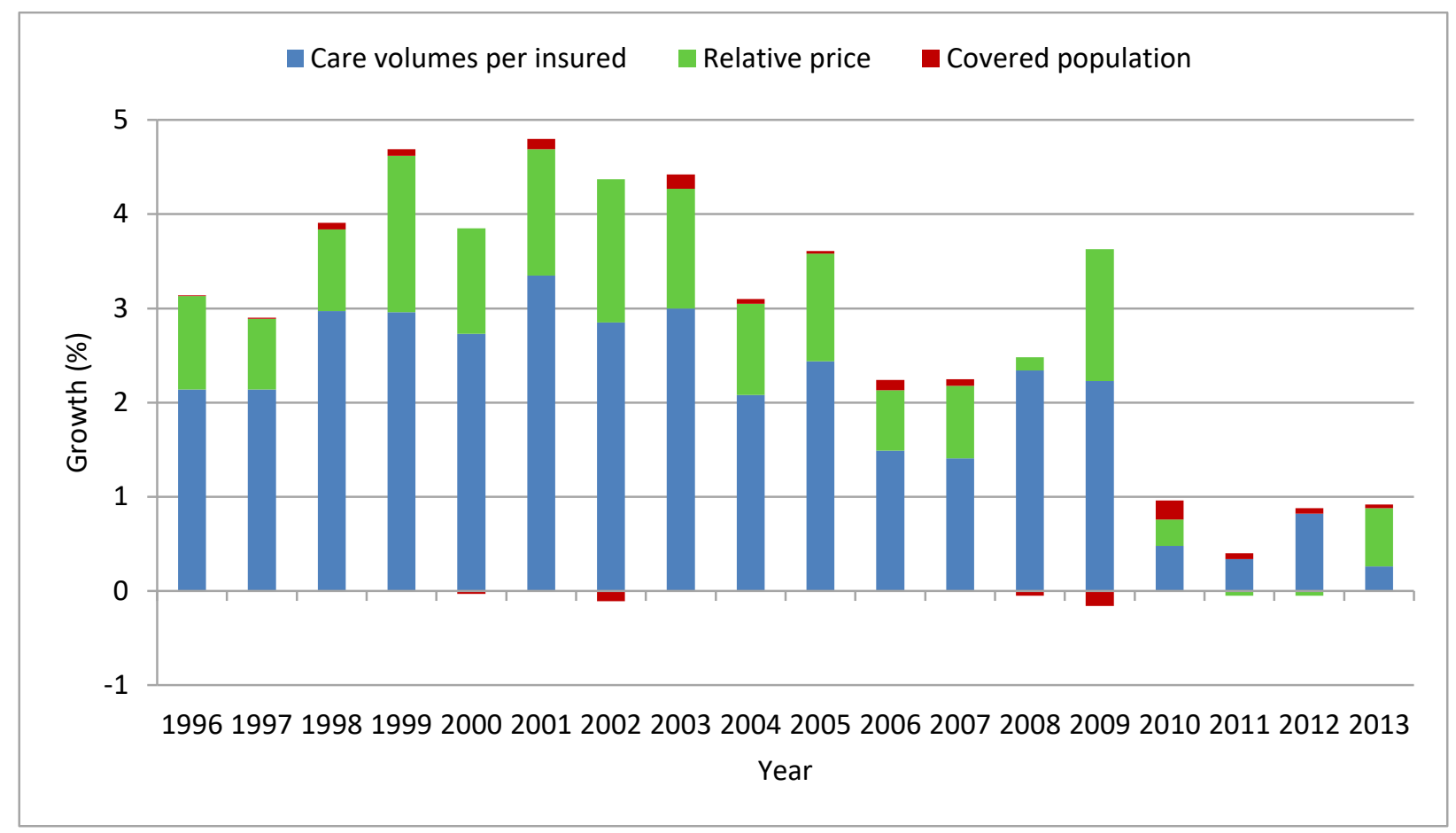

Includes data for Austria, Belgium, Canada, Czech Republic, Germany, Denmark, Finland, France, Hungary, Iceland, Israel, Italy, Japan, Republic of Korea, the Netherlands, Norway, New Zealand, Portugal, Slovenia, Switzerland, United Kingdom and the United States

Source: OECD Health Statistics 2016 


\subsubsection{Sources of financing and the slowdown of health care expenditure}

19. To examine whether particular financing sources played a role in the slowdown of health care expenditure, we decompose real expenditure growth by private funding, government funding, external funding, and other. To do this, we decompose overall nominal expenditure growth into contributions from source of financing category $j$ using the following formula:

$$
\operatorname{cont}_{t}^{j}=\frac{100}{E_{t-1}^{H}}\left(E_{t}^{j} \cdot \frac{P_{t-1}^{A I C}}{P_{t}^{A I C}} \cdot \frac{N_{t-1}}{N_{t}}-E_{t-1}^{j}\right)
$$

where $E_{t-1}^{H}$ is the nominal total health care expenditure at time $t-1, E_{t}^{j}$ is the nominal expenditure funded by source $j$ at time $t, N_{t}$ is the country's population at time $t$, and $P_{t}^{A I C}$ is the AIC price deflator. We then regress these contributions on the same set of year dummies and country fixed effects. The results of this exercise are shown in Figure 3, alongside a $95 \%$ confidence interval of the year effects. 
Figure 3. Contribution to the cross-country health care expenditure slowdown by source of funding
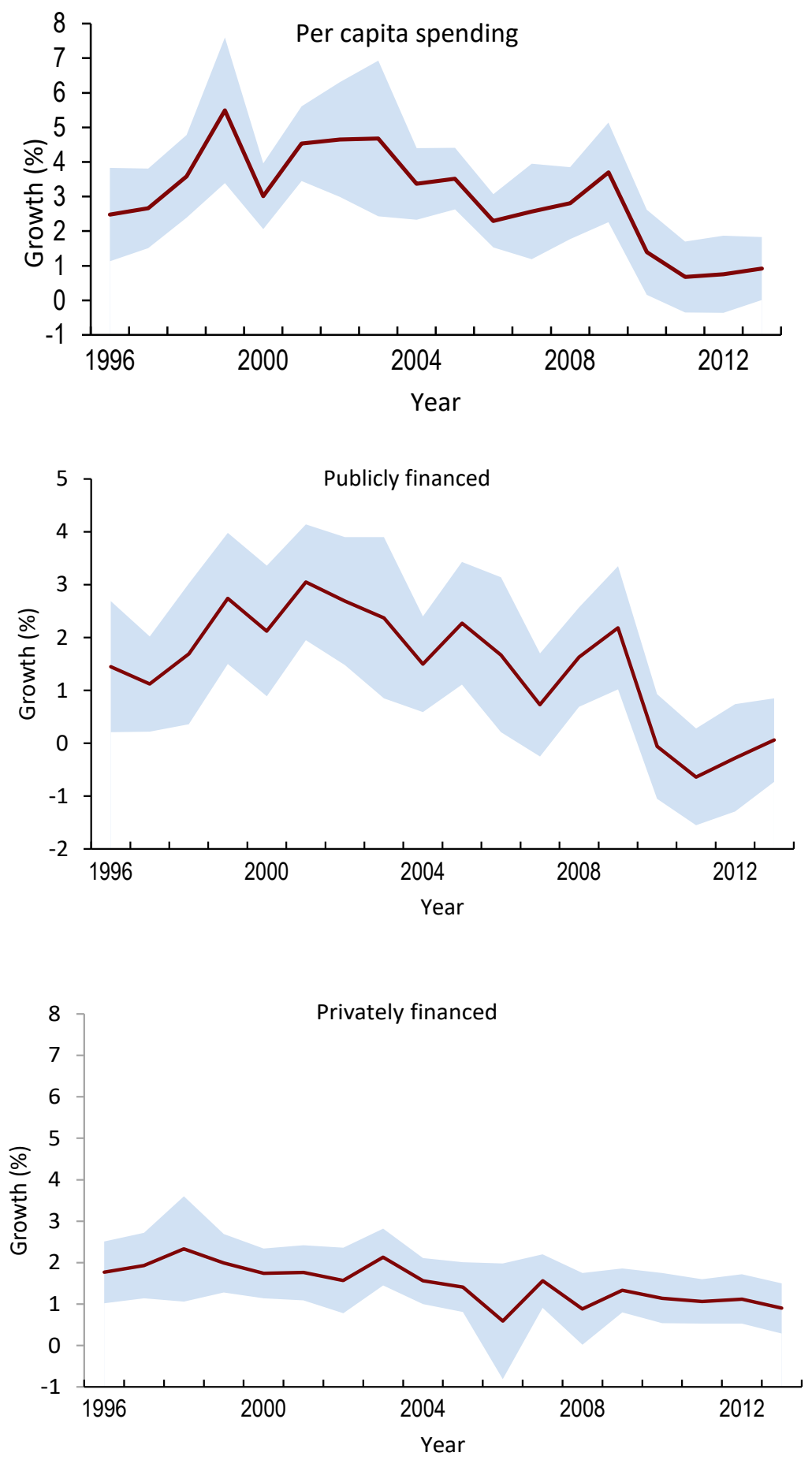

Includes data for Austria, Belgium, Canada, Czech Republic, Germany, Denmark, Finland, France, Hungary, Iceland, Israel, Italy, Japan, Republic of Korea, the Netherlands, Norway, New Zealand, Portugal, Slovenia, Switzerland and the United States

Source: OECD Health Statistics 2016 
20. These panels show that the deceleration in real expenditure is partly from government-financed expenditure and partly from privately financed expenditure. However, contributions from privately-financed expenditure appears to be following a slow and steady deceleration, while contributions from publically financed expenditure growth appear to be more cyclical and the impetus to deceleration from this source intensified in the aftermath of the crisis. Contributions from external and other sources of financing show no material cross-country trends.

\subsubsection{Cyclical vs structural effects}

21. The decompositions discussed above show that the deceleration in health care expenditure intensified in the aftermath of the economic and fiscal crisis, especially for expenditure financed by government. This suggests that structural changes may be playing a role in the more-recent slowdown. Our panel approach may be particularly informative for this type of analysis, as the short samples involved make it difficult to disentangle trend and cyclical developments in health care expenditure. The crosssectional dimension of our sample adds information that may help disentangle such cyclical effects from more structural influences.

22. In an attempt to isolate cyclical influences, we augment the fixed time and country effects in our baseline model with additional controls for each country's economic slack. Since it is not obvious that this effect will be linear or constant through time, we experimented with functional forms that encompassed a number of alternatives that seemed reasonable on a priori grounds. Among other things, neither is it readily apparent whether the level or the change in economic slack is most relevant for identification, nor is it obvious what measure slack is most useful. We do not have a good a priori sense of whether the sensitivity of expenditure to cyclical influences is different for high-spending countries than for other countries.

23. Beyond these issues, asymmetries could arise for a number of plausible reasons, such as if budgetary pressures on government health care expenditure are more binding in a cyclical downturn than in an upturn, or if cyclically unemployed workers cut back on health care consumption because they lack the means to fund co-payments or become uninsured. Similarly, it seems reasonable to suspect that the marginal effect on expenditure growth of a change in economic slack might vary with the magnitude of slack, such as if cyclically unemployed workers rely on employment-linked insurance from their spouses, and their spouse subsequently loses their job (which a particularly relevant scenario the United States). In addition, pressures brought on by the economic and fiscal crisis may have caused some sort of change in how health care expenditure reacts to unemployment, such as if the prolonged budgetary pressures unleashed by the crisis prompted greater restraint on government-funded health care expenditure than in previous downturns. Finally, since it is not readily apparent which measure of economic slack is most useful for identification, we tried our results using country-specific OECD measures of both the annual unemployment rate gap and the annual output gap.

24. Figure 4 shows how cyclical influences have contributed to the cross-country time trend in health care expenditure, decomposing the time effects from our basic panel regression framework after augmenting this specification with linear terms for both the level and the change in the unemployment rate gap (both of whose estimated coefficients 
are highly significant and negative) $)^{5}$. The figure compares the overall cross-country time effects - the red line - with estimated effects from our analogous earlier specification that controls for slack for the panel of 22 OECD countries - the blue line - and for the highspending countries - the green bold line ${ }^{6}$.

Figure 4. Cyclical influences explain only some of the cross-country slowdown in health care expenditure

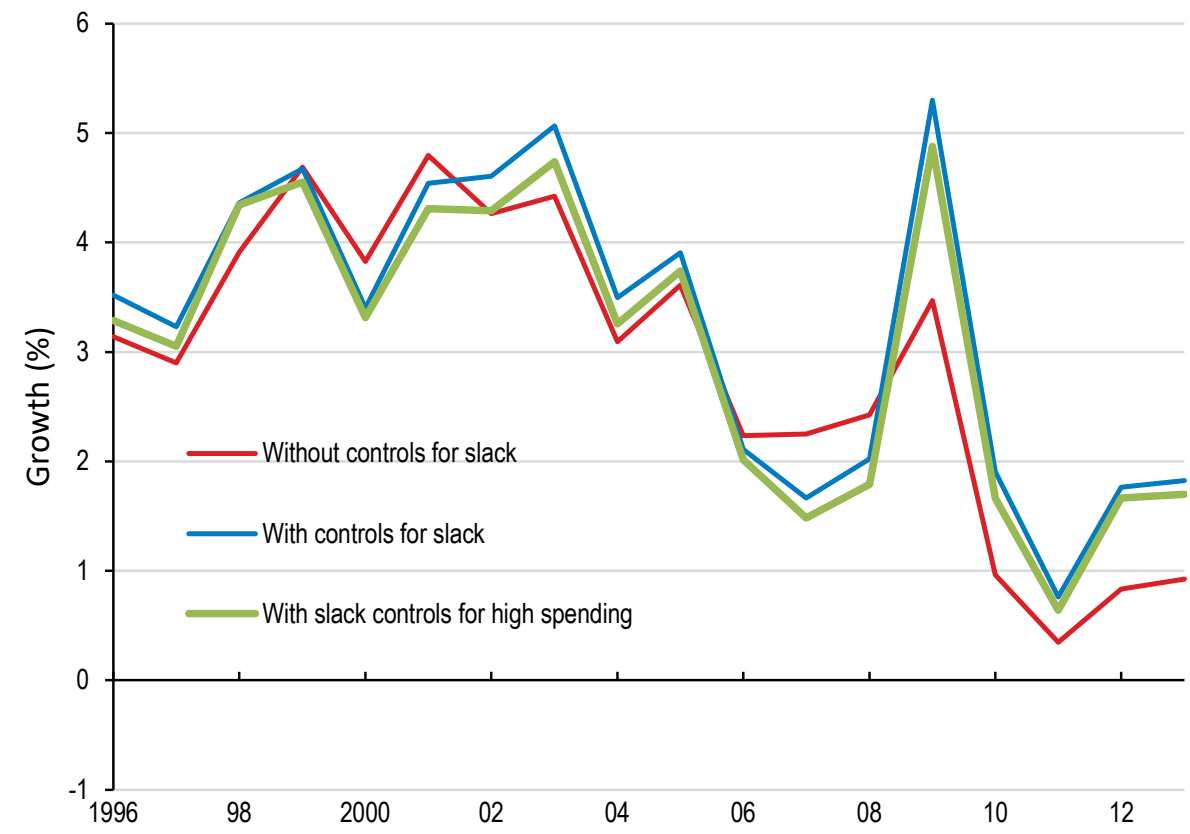

"High spending" countries include Canada, Denmark, France, Germany, Japan, the Netherlands and the United States

Source: OECD Health Statistics 2016

25. Trend expenditure growth is higher following the crisis after controlling for slack, suggesting that cyclical influences have contributed to the health care expenditure slowdown. Nonetheless, health care expenditure growth still trends downward, on balance, after controlling for slack, which suggests that structural influences are also at play.

26. The average growth rate of health spending was $2.6 \%$ annually between 2005 and 2008 - which was roughly the peak of the cycle - and fell to $0.7 \%$ annually between 2010 and 2013 (we exclude 2009 due to the effect of the idiosyncratic oil price change on the deflator). When controlling for the effects of slack the growth rates in per capita spending

5. We obtain similar results when we replace the unemployment rate gap with the OECD's measure of the output gaps for each country (not shown).

6. It is worth noting that, once again, those sets of estimates show that relative price effects from the collapse of energy prices in 2009 coincide with a noticeable transitory jump in real spending growth. 
for the same periods were $2.4 \%$ and $1.5 \%$. These figures suggest that cyclical factors may account for a little less than one half of the estimated slowdown in health care spending between the two periods.

27. Table 1 shows some robustness tests for the cyclical effects on overall health care expenditure growth, starting with the simple specification discussed above in column 1 . The second column allows the sensitivity of the cyclical effect to differ for the group of eight high-spending countries (denoted by the dummy variable Dhigh=1). These estimated coefficients suggest that expenditure growth is much more sensitive to cyclical fluctuations in these high-spending countries; indeed, although the effects for the overall group of 22 countries are negative, they are difficult to distinguish from zero at standard significance levels. By comparison, health care expenditure growth in the high-spending group is highly sensitive to both the change and the level of economic slack. Column 3 tests whether there is an asymmetry in the cyclical sensitivity for cases where the unemployment rate is below its natural level (denoted by $D t-=1$ ), column 4 tests whether expenditure became more sensitive to cyclical fluctuations after the economic and fiscal

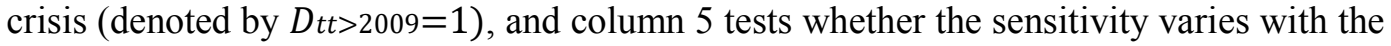
size of the unemployment rate gap. Column 6 includes all of the effects shown in columns 3 through 5. As you can see, these various nonlinear terms are weakly significant at best, and tend to be susceptible to instabilities that can arise with colinearity in small-samples. Overall, we interpret these coefficients as providing weak only weak evidence for these nonlinearities, at best.

28. We find little evidence that the year fixed effects for the set of high-spending countries is statistically different from that of the overall set of countries, after controlling for cyclical effects. The green line in Figure 4 shows the time pattern of year effects after allowing the cyclical effects for the high-spending group to differ from the overall group as in column 2 of Table 1. The effects are broadly similar to those from the more basic specification, again suggesting that cyclical effects explain some, but not all, of the health care expenditure slowdown. The chart is not materially different when we include the nonlinearities in the cyclical effect shown in Table 1.

\subsubsection{Functional expenditure and the slowdown of health care expenditure}

29. To gain insight into the sources of the broad-based slowing in real health care expenditure that can help inform further analysis, we estimate the contribution to overall expenditure growth from of each of the main functional expenditure categories. Analogous to the previous section, we decompose overall nominal expenditure growth into contributions from functional expenditure category $i$ using the following formula:

$$
\operatorname{cont}_{t}^{i}=\frac{100}{E_{t-1}^{H}}\left(E_{t}^{i} \cdot \frac{P_{t-1}^{A I C}}{P_{t}^{A I C}} \cdot \frac{N_{t-1}}{N_{t}}-E_{t-1}^{i}\right)
$$

where $E_{t-1}^{H}$ is the nominal total health care expenditure at time $t-1, E_{t}^{i}$ is the nominal expenditure on the expenditure category $i$ at time $t, N_{t}$ is the country's population at time $t$, and $P_{t}^{A I C}$ is the AIC price deflator. We then regress the available panel of these contributions for each expenditure category in the same set of year dummies and country fixed effects. In principle, the sum of these time effects across expenditure categories in each year would sum to the overall time effects shown in Figure 1; however, since the available sample for these contributions is somewhat smaller than the overall sample due to missing data, there are some minor discrepancies from year to year. 
30. Figure 5 shows the time pattern of the estimated contributions to the overall effects from each of the major functional categories - along with a $95 \%$ confidence interval in the shaded area. These figures show that the deceleration in overall expenditure is focused almost entirely in just two categories: curative and rehabilitative care, and medical goods. 
Figure 5. Contribution to the cross-country health care expenditure slowdown by functional expenditure category
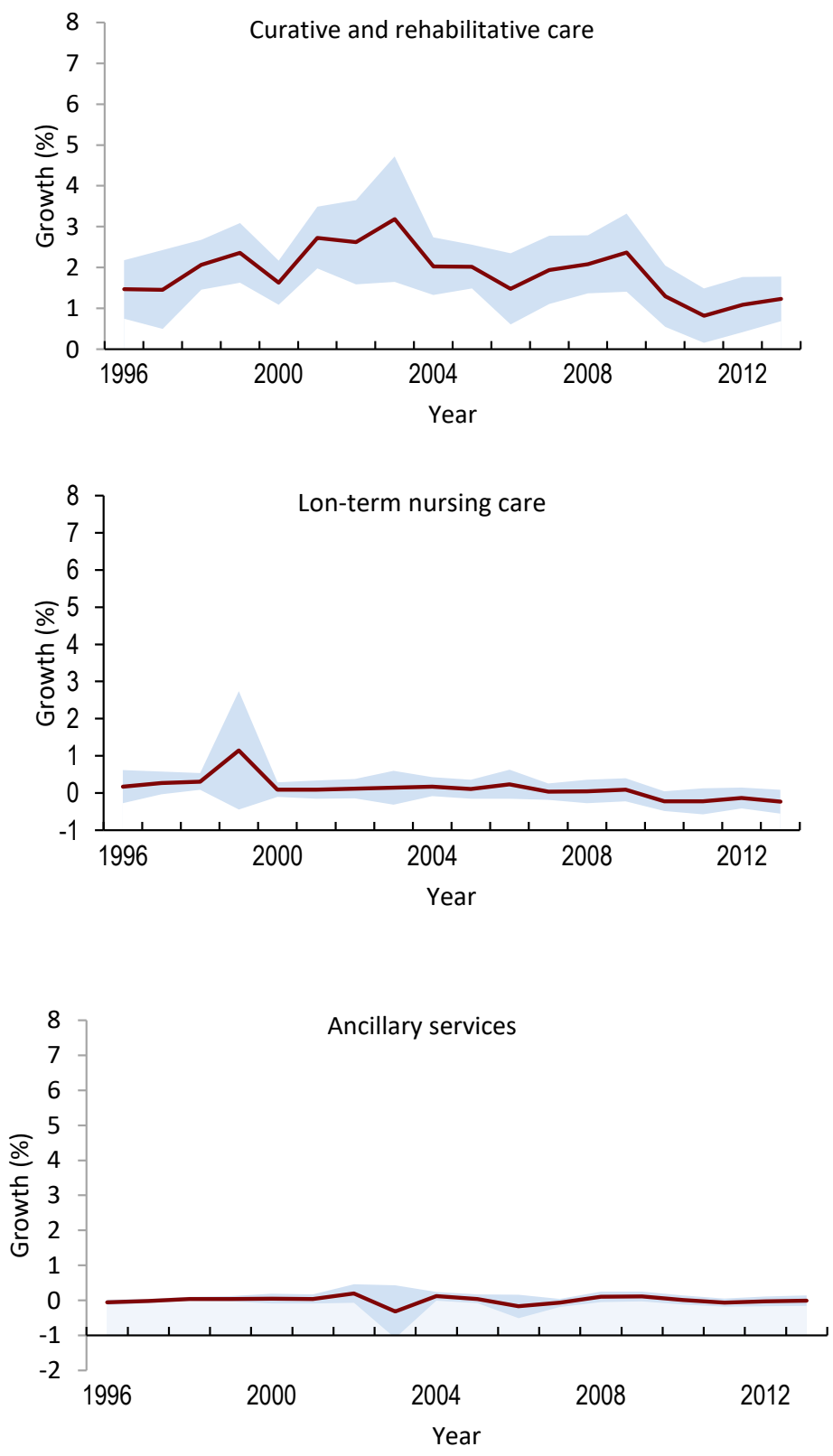

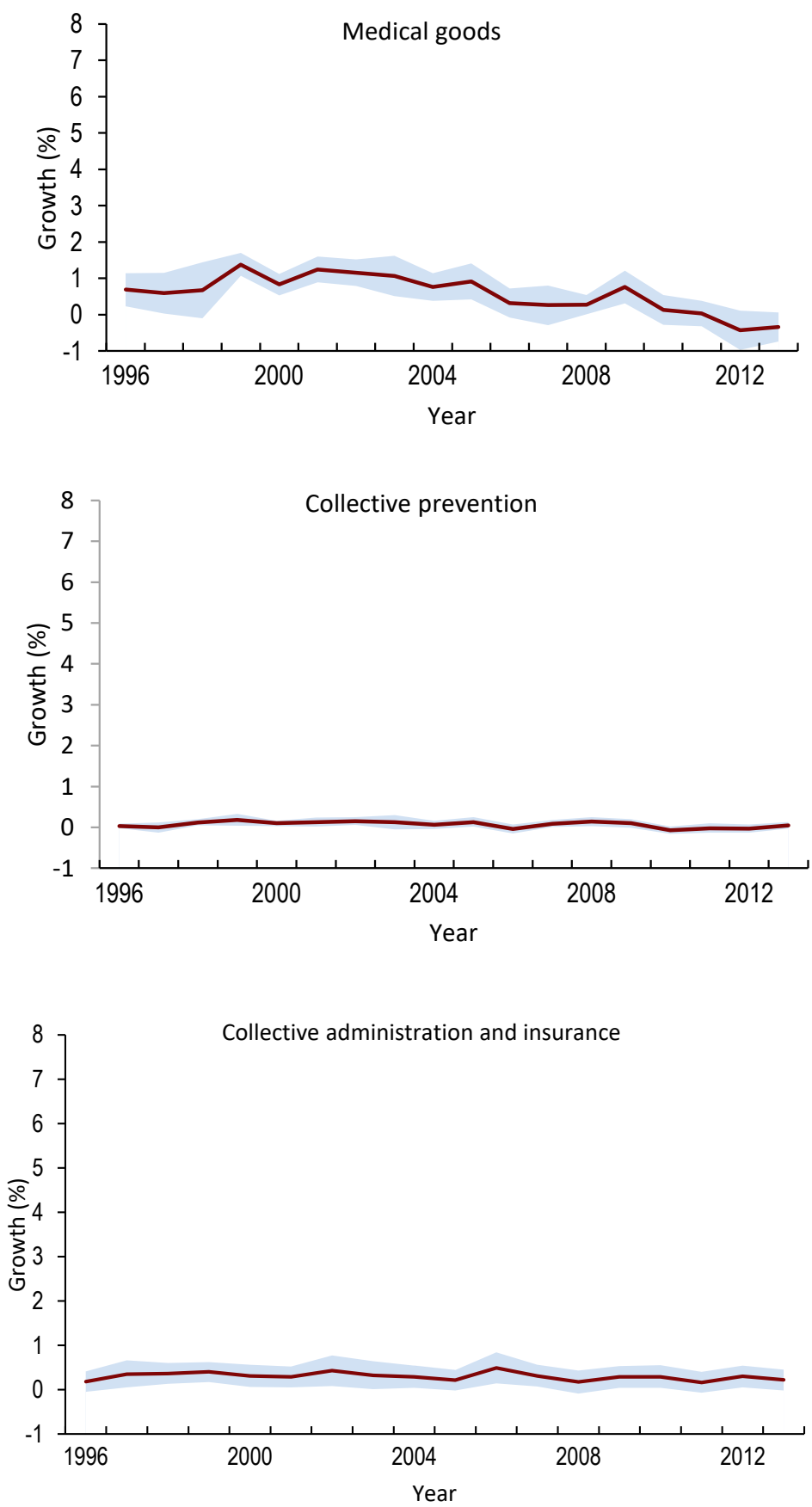

Includes data for Austria, Belgium, Canada, Czech Republic, Germany, Denmark, Finland, France, Hungary, Iceland, Israel, Japan, the Netherlands, Norway, Portugal, Slovenia and the United States

Source: OECD Health Statistics 2016

31. Figure 6 drills down into the sources of the deceleration in these two categories by looking at contributions from the detailed subcomponents of these two categories. Panel A breaks down the contribution to the overall trend from the curative and rehabilitative care category into its available subcomponents, showing that the 
deceleration from this category is partly from inpatient cases and partly from outpatient care. Panel B does the same decomposition for medical goods, showing that the deceleration from this category is entirely from pharmaceuticals and other non-durables. In turn, Panel $\mathrm{C}$ shows that the deceleration from pharmaceuticals is mainly concentrated in prescribed medicines - whose contribution has been decelerating since the early $2000 \mathrm{~s}$ and has been essentially flat since the economic and fiscal crisis. 
Figure 6. Contribution to the cross-country health care expenditure slowdown by selected functional expenditure sub-categories
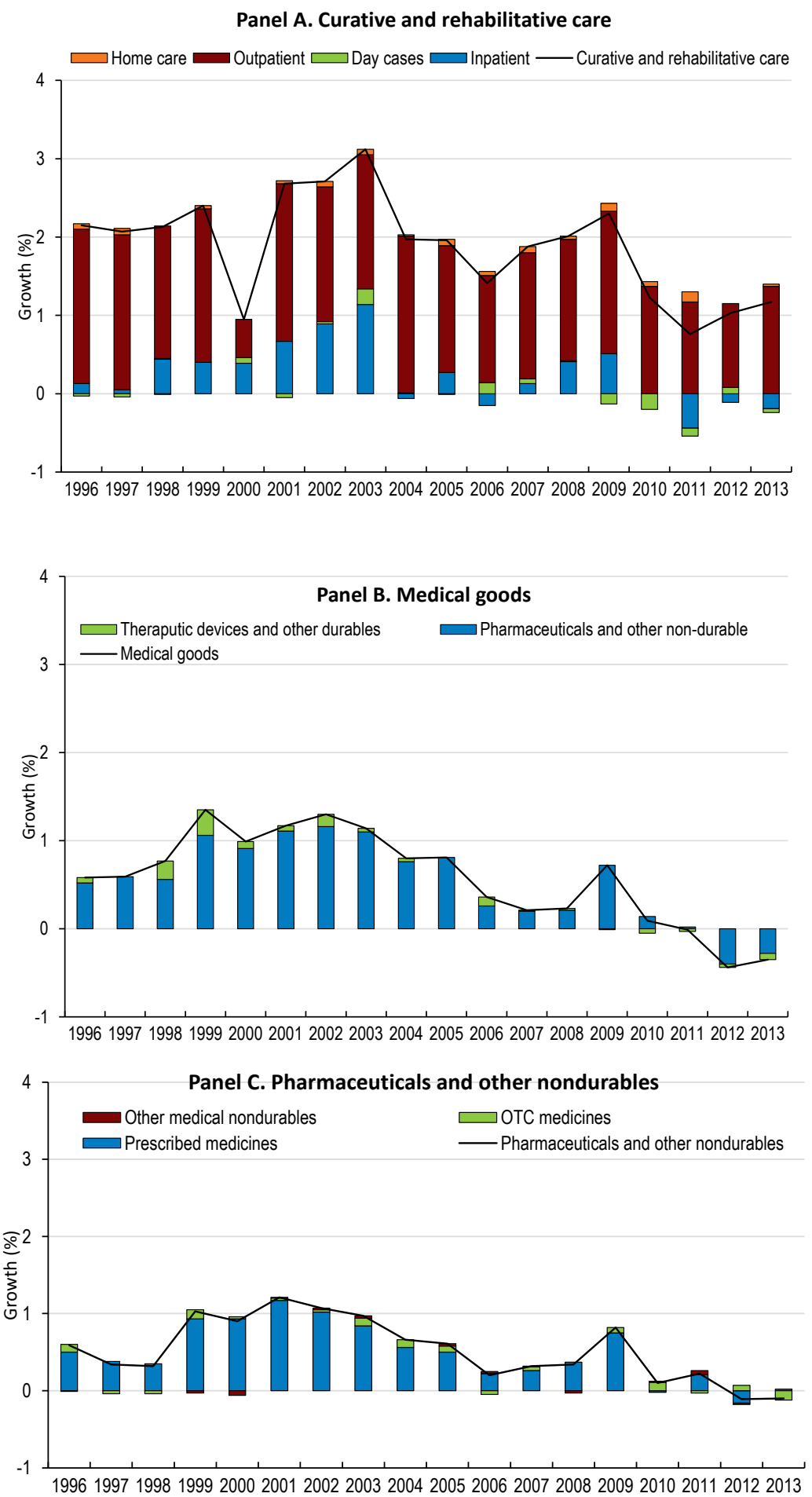

Includes data for Austria, Belgium, Canada, Czech Republic, Germany, Denmark, Finland, France, Hungary, Iceland, Israel, Japan, the Netherlands, Norway, Portugal, Slovenia and the United States

Source: OECD Health Statistics 2016 
32. Drilling down further into the detail for each of the funding categories, we decompose each of the main functional expenditure categories contributions in overall expenditure growth into portions from publicly and privately-financed expenditure. Figure 7 shows this breakdown for government-financed expenditures, while Figure 8 shows the same breakdown for privately financed expenditures.

Figure 7. Contribution to the cross-country publicly financed health care expenditure slowdown by functional expenditure sub-categories

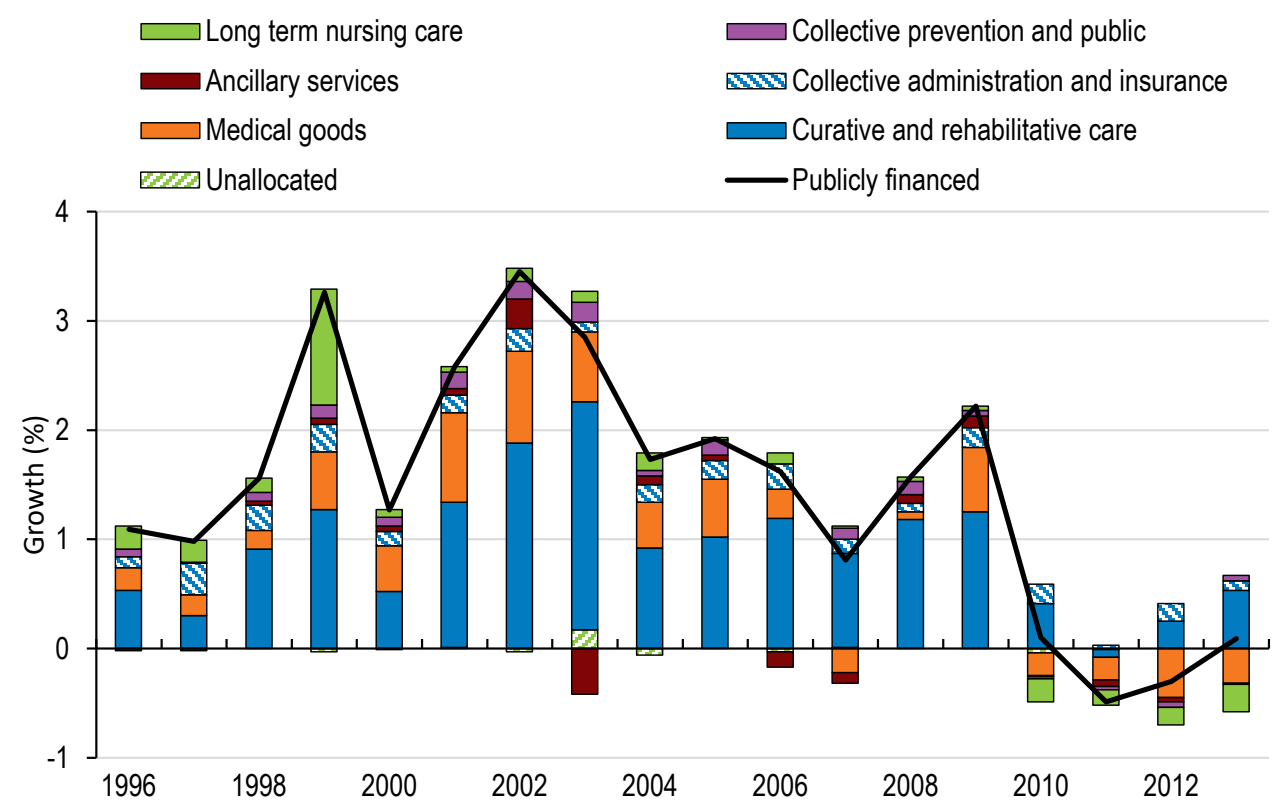

Includes data for Austria, Belgium, Canada, Czech Republic, Germany, Denmark, Finland, France, Hungary, Iceland, Israel, Japan, the Netherlands, Norway, Portugal, Slovenia and the United States

Source: OECD Health Statistics 2016 
Figure 8. Contribution to the cross-country privately financed health care expenditure slowdown by functional expenditure categories

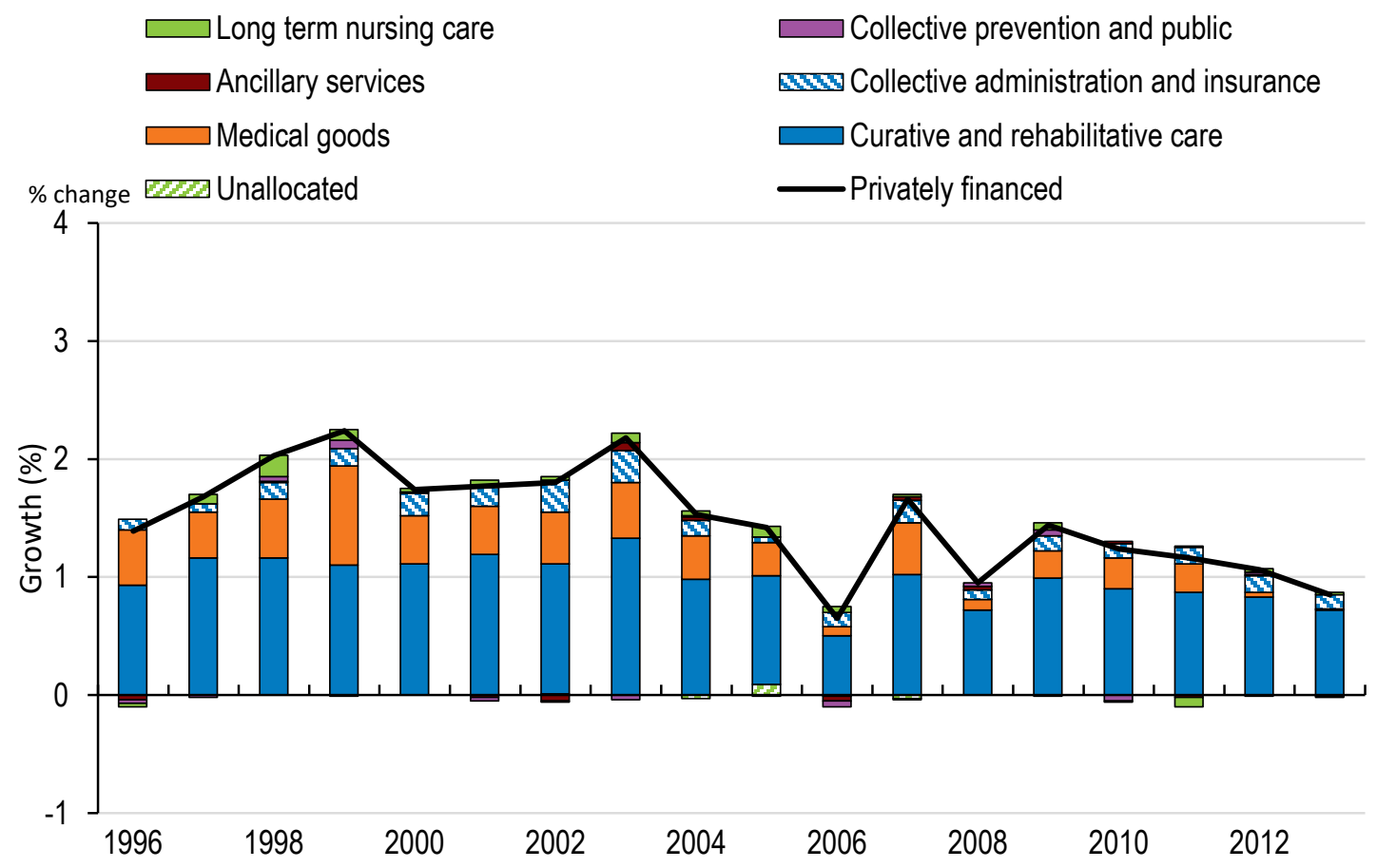

Includes data for Austria, Belgium, Canada, Czech Republic, Germany, Denmark, Finland, France, Hungary, Iceland, Israel, Japan, the Netherlands, Norway, Portugal, Slovenia and the United States

Source: OECD Health Statistics 2016

33. These results show that the impetus to the overall slowing in health care expenditure from government-financed sources is concentrated in the curative and rehabilitative care category (particularly after the crisis), and, to a lesser extent, in medical goods. Meanwhile, the impetus to the slowing in overall expenditures from privately-financed sources is mainly reflected in a very gradual downtrend in the contributions from curative and rehabilitative care category and from medical goods.

34. Pharmaceuticals and hospital care are areas where there have been significant changes in policies by different countries, which are discussed below.

\subsection{Key policy changes in the study period}

35. We analyse key policies and policy changes in the US and other high-spending countries in three areas - coverage, prescription drugs, and hospital inpatient care - to provide information about the factors and forces that have driven the reported deceleration in health care expenditure (Bradford et al., 2011) (Box 1). Important policy changes have been made in these areas in recent years, with substantial effects on health care expenditure in the countries of interest. Changes also occurred in other areas (such as ambulatory care) not covered in this paper. 


\subsubsection{Coverage, institutional set up and scope}

\section{Changes in coverage}

36. Changes to coverage in the group of high-spending countries are only evident in the United States and to a far lesser extent in Germany.

37. The US has the largest proportion of the population without health care coverage in the OECD area. In 2014, almost 33 million people $-10.4 \%$ of the total population were not covered by any type of insurance for the entire year (Smith et al., 2015). However, the number of people who were uninsured decreased importantly after the 2009 economic and fiscal crisis, and further major expansions of coverage are eventually expected to occur in line with mandates in the 2010 Patient Protection and Affordable Care Act (ACA).

38. Most of the US population is covered by employer sponsored insurance (ESI) plans (175 million in 2014). As an effect of the ACA, the public programme Medicaid took on an additional 7 million beneficiaries in 2014, while 5.4 million people gained access to health insurance through the Marketplace (Centers for Medicare and Medicaid Services, 2015).

39. Medicare beneficiaries are projected to increase to 75 million in $2026,60 \%$ more than in 2010, as growing numbers of baby boomers turn 65 and become eligible for benefits. Medicaid is expected to take on an additional 9 million beneficiaries from 2015 to 2026, largely in States that had expanded eligibility for their Medicaid programs (Congressional Budgetary Office, 2016a). Taking also into account the number of people who will predictably enrol in insurance exchanges, the number of uninsured is projected to drop to 27 million in 2025 (Congressional Budgetary Office, 2015).

40. Coverage issues were addressed in several high-spending countries during the study period, but to a far lesser extent than in the US, because those countries already had virtually universal coverage. In fact, some of those countries adopted measures to restrict the scope of their health coverage as a way to cope with increasingly tight fiscal constraints.

41. In Germany, the 2009 Statutory Health Insurance Competition Strengthening Act made health insurance compulsory for all (less than $1 \%$ were previously uninsured) and required private insurers to offer at least a basic benefit package, broadly equivalent to the statutory package (Paris et al., 2010). 11\% of the population are privately covered for basic health insurance, whereas the rest are covered by the statutory insurance programme funded through income-related contributions. Another $0.3 \%$ of the German population benefits from insurance that is covered by the state.

\section{Changes in institutional set up}

42. In a number of countries, the institutional set up of health care delivery was changed during the period under consideration.

43. In 2006, the Netherlands introduced a new universal health insurance scheme, replacing a dual system of public and private insurance. The scheme is partly financed by income related payroll contributions into a Health Insurance Fund, and partly by a flatrate nominal premium to competing health insurance funds (Schäfer et al., 2010).

44. In Switzerland, individuals purchase health insurance from competing funds, with means-tested subsidies for lower-income households. In both the Netherlands and 
Switzerland, health insurance funds cannot deny an insurance policy to an applicant and are not allowed to charge different nominal premiums adjusted for the individual's risk profile. Universal coverage is provided in France through different social health insurance funds, with the main one-Caisse Nationale de l'Assurance Maladie des Travailleurs Salariés, or CNAMTS - covering about $80 \%$ of the population (all salaried workers and their families, and the unemployed and the poorest fringes of the population). In France, the national benefit package is generous in scope, but involves co-payments, for which nearly the entire population ( $96 \%$ in 2010) resorts to complementary insurance.

45. A residence-based tax-funded health care system ensures universal coverage in Canada. The administration and delivery of health care services are the responsibility of each province or territory, according to the Canada Health Act, passed in 1985 and amended several times thereafter. Covered health care services include primary health care and care in hospitals. Most provincial and territorial governments fund a range of additional services.

46. All those registered as residents can access free primary and specialist health services in Denmark. Since 2007, the system is mainly financed through an $8 \%$ health contribution tax on income. Approximately $40 \%$ of the population purchase private health insurance to cover additional costs arising from dental care, outpatient drugs and corrective lenses (Vrangbæk, 2015).

47. In Japan, a public health insurance system introduced in 1961 provides universal primary coverage for all residents and citizens. More than $70 \%$ of the population subscribe to an additional voluntary private insurance to cover long hospitalization periods or receive lump-sums when chronic diseases are diagnosed (Matsuda, 2015). The growing burden of the ageing population on the National Health Insurance (NHI), has led to the introduction of a new program for the elderly ( 75 and above) in 2008 , to which the entire insurance system as well as those covered contribute based on their income (Kobayashi, 2009).

\section{Changes to scope}

48. Several measures are used to limit the scope of the health coverage in highspending countries. Switzerland has a general annual deductible of CHF 300 (\$324) for all services, although people can choose insurance contracts with lower premiums and higher deductibles (up to CHF 2500 [\$2699] per year) (Leu et al 2009). In the Netherlands, the current general deductible is EUR 350 (up from $€ 150$ in 2009) and, after the crisis, charges for specific services (e.g. in-vitro fertilisation, physiotherapy, and some mental health services) were introduced or increased and the coverage of care outside the European Union was removed (Mladovsky et al 2012). In France, in 2008 private voluntary health insurance stopped reimbursing new user charges for prescription drugs, physician visits, and ambulance transport; statutory health insurance copayments for patients not following agreed medical pathways were increased and reimbursement rates for specific medicines and medical procedures were reduced.

49. Countries have also imposed deductibles for some categories of services (e.g. pharmaceuticals). These deductibles are described in the following sections.

\section{Pharmaceutical expenditure}

50. Measures to contain expenditure on pharmaceuticals were introduced and intensified in the aftermath of the crisis (Belloni et al 2016). Expenditure growth rates fell 
sharply in all eight countries, and became negative, with the exception of Japan and Switzerland, between 2009 and 2013 (Figure 9).

Figure 9. Per capita pharmaceutical expenditure (in real terms at 2005 US\$ Purchasing Power Parities) trends across selected OECD countries, 1996 - 2013

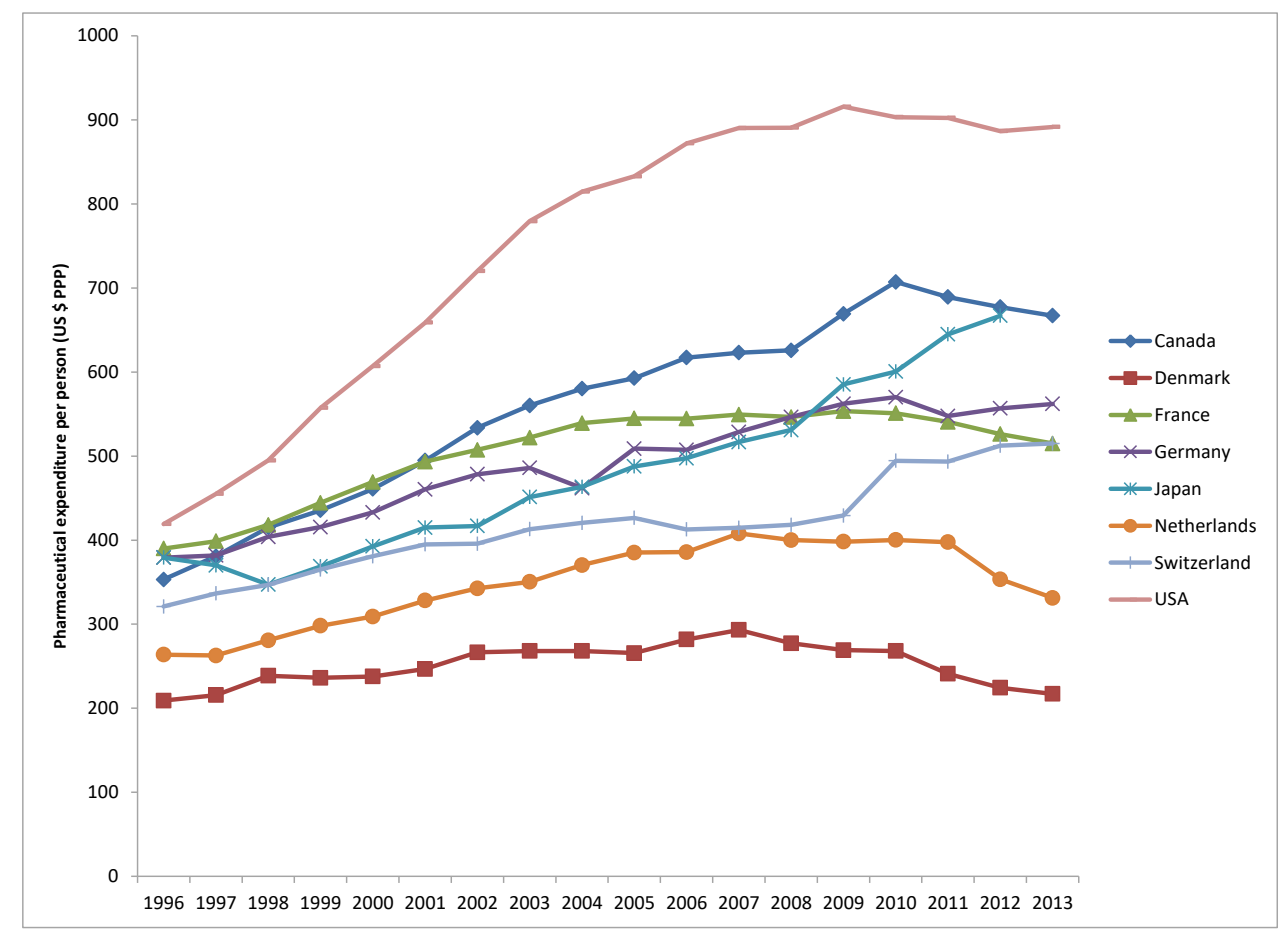

Source: OECD Health Statistics 2016

51. In the US, the deceleration in pharmaceutical expenditure happened despite a continuing growth in pharmaceutical prices $(2.3 \%$ in 2013) (Centers for Medicare and Medicaid Services 2015). Pharmaceutical prices have been historically higher in the US than in other OECD countries because few barriers to market entry exist after US Food and Drug Administration approval, and less price regulation occurs (see Box 1 further below). However, an increase in the number of generic drugs consumed- $80 \%$ of total prescriptions dispensed in 2013-driven largely by the loss of patent protection for numerous blockbuster drugs helps explain the negative growth in pharmaceutical expenditure per capita observed in the US after the economic downturn (Thorpe et al. 2015).

52. Medicare Part D, a voluntary outpatient drug benefit programme, was introduced in 2006, amounting to the largest expansion of Medicare since its establishment. The programme subsidises participating private prescription drug plans. Drug prices are established through a negotiation of rebates between individual plans and drug manufacturers. By law, central price negotiations are not allowed within Medicare, whereas they are possible in Medicaid. Rebates negotiated by Part D plans $(12.9 \%$ on average in 2013) (The Boards of Trustees 2015) were substantially lower than statutory Medicaid rebates for the same branded drugs $(23.1 \%$ of average manufacturer price for brand drugs and $13.1 \%$ for generics). However, the Centers for Medicare and Medicaid Services is required under the ACA to establish a "coverage gap discount program", through which branded drug manufacturers provide a $50 \%$ discount on covered drugs 
purchased by Medicare beneficiaries beyond an initial expenditure limit and up to a catastrophic coverage threshold (a so-called doughnut hole) (Zhang et al. 2009; Shrank et al. 2011).

53. The introduction of Part $\mathrm{D}$ resulted in a slight increase in average drug utilisation and a decrease in average out-of-pocket expenditures. Coverage genuinely increased, but many beneficiaries were simply shifted across different types of insurance (mainly from Medicaid and private plans). Part D beneficiaries increased from 22.5 million in 2006 to more than 39.3 million in 2015 (Hoadley et al. 2015), and the share of prescription drug expenditure financed by Medicare increased from 1.9\% in 2005 to $29 \%$ in 2014, whereas the share financed by Medicaid decreased from $17.8 \%$ to $9.2 \%$ during the same period (Centers for Medicare and Medicaid Services 2015).

54. Other high-spending countries were subject to similar inflationary pressures linked with technological innovation in the pharmaceutical sector, but not to the pressures generated by expansions of coverage. Despite this, and despite a broader availability of incisive cost control approaches in more centralised systems, the expenditure outcomes were not substantially different from those reported in the US. This was the result of a number of different approaches.

\section{Price reviews and changes to reimbursement}

55. Countries' efforts to rein in pharmaceutical expenditure focused on lowering prices and redefining reimbursement rules. Swiss authorities undertook an extraordinary price review of 2000 drugs in 2009. The price of reimbursed medicines was re-examined to be in line with six comparator countries (Austria, Denmark, France, Germany, the Netherlands and the United Kingdom), with a 4\% tolerance margin to compensate for shifts in currency exchange rates. Measures recently implemented include a periodic reexamination of prices every three years as well as a systematic review of the price of products for which a new indication has been approved. In 2010, Germany introduced a price freeze on ex-factory prices of reimbursable medicines with retrospective effect from August 2009. Additionally, pharmaceutical companies' rebates to Sickness Funds on pharmaceutical prices were increased from $6 \%$ to $16 \%$ for non-reference-priced drugs. Those manufacturers' rebates were then reduced to $7 \%$ for patented drugs and to $6 \%$ for off-patent drugs in 2014.

\section{Using reference prices}

56. Other high-spending countries use international or external reference pricing to regulate pharmaceutical prices, at least for some market segments. On the contrary, the US relies on market competition to provide the right incentives and only set limits to prices billed o Medicaid. In Canada and France, reference prices are used as the main criterion to set prices only for medicines with substantial added benefit, whereas in Denmark the scope is limited to new hospital-only medicines. In Switzerland all medicines reimbursed by the public health care system are within the scope on international benchmarking, while in the Netherlands reference prices are used for prescription-only medicines, and high-cost medicines and orphan drugs for inpatient care.

57. Japan used reference prices to adjust the prices of all reimbursed medicines, while in Germany reference prices provide support information for new medicines with additional therapeutic benefit for which the national association of health insurance funds negotiates the reimbursement price with pharmaceutical companies. 


\section{Pricing generics}

58. Several countries implemented generic price link systems, setting maximum prices or lowering existing ones for generic products. For instance, several provinces in Canada introduced price caps on generics of between 25\% (Ontario) and 56\% (Alberta) of the prices of corresponding branded products (originator prices) (Anis et al. 2011). As of April, 2013, Canada's provinces and territories (except Quebec) capped the prices of ten widely prescribed generic drugs at $18 \%$ of their branded equivalents (Law et al 2011). Similar price reductions apply for four generics in 2015 and four in 2016. The PanCanadian Generic Pricing Framework (2014) introduced a progressive tiered approach to generic price linkage that set generic prices from $75 \%$ to $25 \%$ of the brand-name price, depending on the number of manufacturers. France limits the price of generics to $60 \%$ of the originator's price, with a further $20 \%$ reduction after 18 months.

59. Since the onset of the economic crisis, countries have strengthened their generic policies also through increased incentives and obligations for physicians, pharmacists and patients. Denmark and Germany mandate pharmacists to substitute the medicine prescribed by the cheapest generic, unless opposed by the prescriber. France introduced a pay-for-performance scheme for pharmacists in 2012 with a bonus for the achievement of targets in terms of generic dispensing. Japan set higher levels for targets to be achieved and the bonus associated with higher target levels for pharmacists in 2012 to further encourage substitution. France (in 2009 and 2012) introduced incentives for general practitioners to prescribe generics through a pay-for-performance scheme while Japan (in 2012) increased the targets to be achieved (share of generics in prescribing) by prescribers to earn the associated bonus. In France, since 2010, when patients refuse a generic substitution they have to pay upfront for their drugs and submit a claim for reimbursement. Although there is no formal evaluation of this measure, its implementation coincided with a remarkable increase in the generic market share. As from January 2015, France allowed physicians to prescribe in international nonproprietary names (INN).

\section{Raising co-payments and setting reimbursements}

60. Co-payments were raised in several countries. In France, a fixed co-payment of $€ 0.50$ per prescription (up to $€ 50$ per year) was introduced in 2008 , while the reimbursement rate for drugs with insufficient therapeutic value was reduced from $35 \%$ to $15 \%$ in 2011 . Switzerland introduced an increased co-payment for branded drugs with cheaper therapeutic equivalents in 2005. In the Netherlands, the insurance deductible applying to all health care services-including pharmaceuticals-has escalated since 2009. In Denmark, people must pay the full cost of medicines up to a certain threshold (deductible) and then pay decreasing co-insurance rates until their annual expenditure reaches a second threshold (annual cap), beyond which costs are fully covered (Vrangbæk 2015). In Japan, patients pay a 30\% co-insurance rate, which is the same for all medicines.

61. An important development in the Dutch pharmaceutical system has been the introduction of the preference policy to obtain more price competition and, as a consequence, lower prices. This policy allows insurance companies to determine one or a limited number of product(s) per product category or medicine cluster (medicines with the same active ingredient, dosage form and strength) as preferred for a set period. The Government still decides whether a medicine is eligible for reimbursement, but the health 
insurance companies may narrow the range of medicines in a cluster for which their company will pay.

\subsubsection{Hospital care}

62. On average, hospital care accounts for about $30 \%$ of total health care expenditure across OECD countries, the biggest individual health care expenditure component. Hospital expenditure growth decreased after 2009 in Canada, Germany and the US (Figure 10); however, it remained positive throughout (except in Denmark), and was higher than in other health care compartments.

Figure 10. Per capita hospital expenditure (in real terms at 2005 US\$ Purchasing Power Parities) trends across selected OECD countries, 2004 - 2013

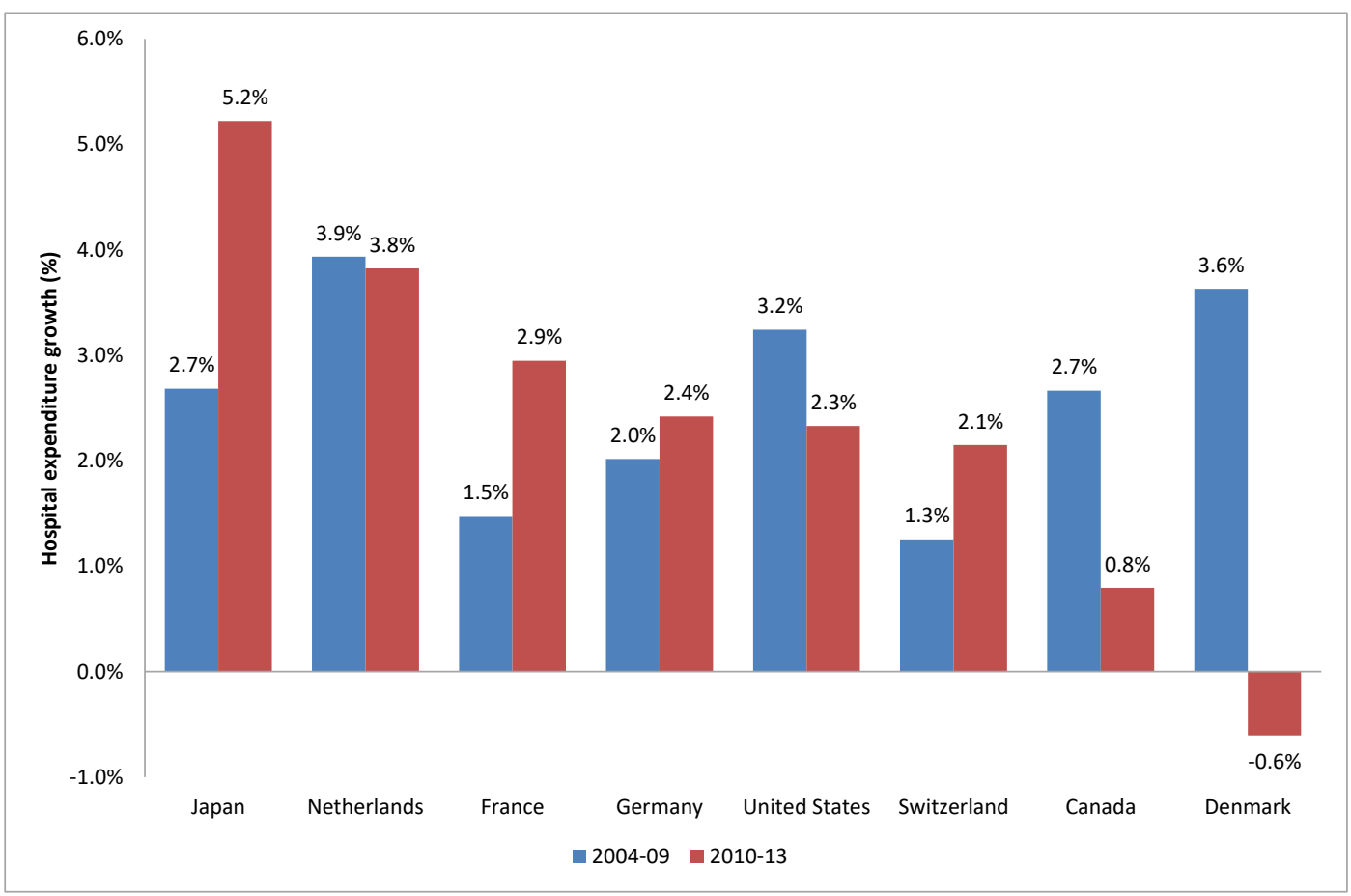

Source: OECD Health Statistics 2016

63. In the US, most hospital care expenditure is channelled through public programmes. The proportion covered by public programmes decreased slightly after the economic downturn to 53\% in 2013 (Centers for Medicare and Medicaid Services 2015). Total inpatient admissions grew $8.1 \%$ from 2000 to 2008, but have declined since then. From 2012 to 2013, inpatient admissions decreased 2.4 percent to around 34 million, close to the number of admission registered in 2000. In 2013, community hospitals provided nearly 678 million outpatient visits, an increase of $30 \%$ from 2000 . The percentage increase from 2012 to 2013 was the lowest observed since 2000 at $0.5 \%$ (MedPac 2015).

64. A stagnation in physician fees might also contribute to explaining the increasing volumes of outpatient activity to substitute for inpatient care. Since 2002, growth in Medicare physician and health professional payments overshot Sustainable Growth Rate (SGR) targets, calling for cutbacks in reimbursement rates. Congress regularly deferred cutbacks, providing for no (in most years), or slight (up to $2.2 \%$ ), updates in the period 
2003-13. Cutbacks might never have been applied, but SGR targets probably contributed to forestalling excessive cost growth.

65. Medicare physician fees are substantially lower than those offered by private insurance plans, and further cuts might have deterred physicians from offering their services to Medicare patients. Against this scenario, the Medicare Access and Chip Reauthorization Act (MACRA) of 2015 transforms the way physicians are paid (Health Policy Brief 2016; Rosenthal 2015). This change marks a new era in which Medicare will adjust payment to medical professionals according to measures of their performance and participation in efforts to improve care and restrain cost growth. MACRA will become the largest pay-for-performance scheme in the world.

66. The hospital sector has been the target of cost containment strategies based on the setting of budgets and the application of direct controls on the supply of health care (Stabile et al., 2013) in other high-spending countries. France, Germany, Japan, the Netherlands, and Switzerland moved towards activity-based hospital payment systems during the study period, whereas British Columbia, Alberta, and Ontario experimented with activity-based funding policies, with the aim of increasing volumes for specific surgical procedures (e.g. hip and knee replacement, cataract surgery) (Sutherland 2011). Some countries adopted global budget systems, in which fixed payments per hospital (e.g. Germany) or for all hospitals (e.g. Netherlands) are negotiated for target levels of activity. Denmark uses DRGs only for paying for activity above annual global budget targets (Socha, 2014).

67. In Germany, funding based on diagnosis-related groups (DRGs) was introduced in 2003-04, whereby hospitals negotiate yearly contracts with sickness funds, detailing service volumes and a proportionate reduction in DRG reimbursement rates applicable if activity exceeds negotiated volumes. Hospitals are legally required to budget prospectively; however, three out of four hospitals are estimated to finalise contracts only late in the budget year (Kumar et al., 2013), which might make this mechanism for controlling expenditure less effective than it could be, as shown by higher and more rapidly rising hospital activity volumes than in comparator countries.

68. A hospital payment system based on a diagnosis treatment combination system was introduced in the Netherlands in 2005. A fixed, centrally determined price is set for $30 \%$ of diagnosis-treatment combinations (Part A), with the remaining 70\% (Part B) being left to volume and price negotiations between health insurers and hospitals. Regulated competition in the hospital sector led to a concentrated market of general hospitals and proliferation of private clinics, often affiliated with hospitals and financed only through Part B (Douven et al., 2012). To limit the effect on expenditure of the volume increase resulting from the above changes, all providers (hospitals, mental health institutions and primary care providers) need to refund the percentage overrun of their own sub-sector, standardised by their own market share (the "macro-controlling instrument") (OECD 2015b).

69. A DRG-based prospective reimbursement scheme for inpatient hospital care was introduced in Switzerland in 2012. DRG-cost weights are applied throughout Switzerland, whereas the base rate (price) is negotiated between hospitals and insurance companies and validated by cantons (the member states of the federal state of Switzerland).

70. A DRG system is also used as the basis of hospital payments in France since 2004-05. The overall financing of the hospital sector occurs within a global budgetary 
envelope for health (and hospitals as a subcomponent) set every year by the government to limit the expenditure of health insurance funds.

71. Japan's DPC system, which is a combination of DRG, per diem and FFS payments, does not provide strong incentives to reduce use of health-care resources (Hamada et al., 2012). Although cost containment was a concern in Japan, the major goal of the prospective payment system was related to improving hospital management and information systems. The purpose of the DPC/per diem payment system (DPC/PDPS) was to deliver quality health-care and to efficiently construct a clinical database by standardizing information platforms (with standardized clinical data), thereby improving the transparency of hospital activities. Standardization, transparency and accountability are the keywords underpinning the aims of the DPC project (Nishioka, 2009).

72. Prospective payment systems were exported from the US to several of the comparator countries, but the US can now learn from the experience of later adopters (Quentin et al., 2013). For instance, in the later-adopting countries, DRGs typically include physician fees (unlike in the US), and prices are mostly set centrally, with more opportunities for expenditure control than in parts of the US health-care system (typically private plans).

73. Patients can access free acute inpatient care in Canada, Denmark and the Netherlands (once general deductibles are paid for). In Germany, a co-payment of EUR 10 per day (USD 12.5) limited to 28 days/year is required, while in France the maximum of $20 \%$ cost-sharing or co-payment of EUR18/day (USD 20.9) should be paid for by patients (except for surgical procedures whose cost exceeds a certain threshold). A coinsurance of $30 \%$ of costs incurred is used in Japan, while in Switzerland the co-insurance is $10 \%$ after deductible, subject to an annual cap.

\subsection{Discussion}

74. In the wake of the financial crisis, health care spending growth slowed markedly in many OECD countries. A key question is how much of the steep post-crisis falloff in health care expenditure growth is cyclical and therefore may reverse as economies continue to recover from the effects of the crisis. Alternatively, the slowdown in health care spending growth may reflect to some extent the influences of policies or other influences that will lead to a more persistent slowdown in spending growth.

75. Disentangling cyclical drivers in health care expenditure from broader trends is particularly difficult for a single country, but more feasible across a group of countries. Examining common trends in expenditure across many countries can help separate the roles of cyclical effects from the impacts of structural factors such as policy measures. In this paper we assess common trends in health care expenditure growth by estimating aggregate effects from cross-country panel regressions, whilst controlling for countryspecific fixed effects. In this study we assess also how cyclicality has contributed to the cross-country downtrend by estimating the aggregate effects for overall per-capita expenditure growth using the same basic specifications, with and without annual measures of each country's economic slack.

76. The results suggest that health care expenditure per person, after accounting for changes in the overall price levels, began to slow in many OECD countries in the earlyto-mid 2000s, well before the economic and financial crisis. The expenditure deceleration was initially gradual in the early-2000s and then intensified around the time of the economic and fiscal crisis. 
77. In order to gain insights about the possible causes of this deceleration we decompose expenditure growth into annual contributions from the volumes of health care consumed per insured person, the price of health care relative to other prices, and the proportion of the population covered by insurance.

78. The decomposition suggests that the gradual deceleration prior to the crisis was driven about equally by slowing in the impact of health care prices growing less slowly than general prices and volumes of health care consumed. The contribution of the sharp post-crisis deceleration appears to have been driven largely by volumes of health care consumed slumping, as well as the continued impact of relative price changes, particularly in 2011 and 2012. The contribution of changes in coverage was minimal.

79. Further decompositions on the basis of source of financing and functional spending category provide additional insights into the nature of the slowdown. The expenditure deceleration to date is most evident in publicly-financed expenditure, which gradually slowed before slowing sharply after of the crisis; by comparison, privatelyfinanced expenditure growth ebbs steadily from the early 2000s onward. By function, the slowdown is most apparent in pharmaceuticals, with government-financed expenditure on curative and rehabilitative care category playing a secondary role, though an important role after the onset of the financial crisis. Privately-financed expenditure growth falls gradually for medical goods and curative and rehabilitive care throughout the sample period.

\subsection{Conclusion}

80. The slowdown in health care expenditure growth is likely to reflect a number of reforms being introduced before and during the period of analysis. Measures to rein in expenditure included ways to control pharmaceutical expenditure by considering pricing, use of generics and changes to co-payment regimes, and the introduction of a number of cost-containment strategies in the hospital sector, such as activity based payment systems. Even the very structure of the health insurance market was subject to reform, most notably in the United States with the introduction of the Affordable Care Act, but also in other countries where reforms to the relationship between the private and public sector were modified. The combined effects of these many policies are likely to lie behind the common trends seen in the evolution of health care expenditure across the OECD.

81. The econometric evidence suggests that structural changes in publicly-financed health care have constrained the growth of care volumes and prices leading to a marked reduction in health care expenditure growth rates, beyond what could be expected based on cyclical economic fluctuations. The aggregate effects suggest that cyclical factors may account for a little less than one half of the estimated slowdown in health care spending between 2005-2008 and 2010-2013.

82. The decompositions and analysis of policy changes suggest that some of the structural changes are policy driven. As a result, while spending growth may accelerate somewhat as economies continue to recover from the financial crisis, the policy changes that contributed to the broader spending slowdown are likely to continue to constrain spending growth in the future. 
Table 1. Robustness of estimated cyclical parameters to alternative specifications

\begin{tabular}{|c|c|c|c|c|c|c|}
\hline Slack Measure & 1 & 2 & 3 & 4 & 5 & 6 \\
\hline$U_{t}-U_{t}^{*}$ & $\begin{array}{r}-0.60 \\
(0.16)\end{array}$ & $\begin{array}{r}-0.33 \\
(0.18)\end{array}$ & $\begin{array}{r}-0.61 \\
(0.25)\end{array}$ & $\begin{array}{r}-0.15 \\
(0.24)\end{array}$ & $\begin{array}{r}-0.24 \\
(0.23)\end{array}$ & $\begin{array}{r}-1.32 \\
(0.48)\end{array}$ \\
\hline$\Delta\left(U_{t}-U_{t}^{*}\right)$ & $\begin{array}{r}-0.84 \\
(0.32)\end{array}$ & $\begin{array}{r}-0.09 \\
(0.28)\end{array}$ & $\begin{array}{r}-0.13 \\
(0.29)\end{array}$ & $\begin{array}{r}-0.12 \\
(0.36)\end{array}$ & $\begin{array}{r}-0.09 \\
(0.28)\end{array}$ & $\begin{array}{r}-0.17 \\
(0.40)\end{array}$ \\
\hline$D^{h i g h}\left(U_{t}-U_{t}^{*}\right)$ & & $\begin{array}{r}-0.43 \\
(0.23)\end{array}$ & $\begin{array}{r}-0.42 \\
(0.24)\end{array}$ & $\begin{array}{r}-0.41 \\
(0.23)\end{array}$ & $\begin{array}{r}-0.42 \\
(0.24)\end{array}$ & $\begin{array}{c}-0.42 \\
(0.22)\end{array}$ \\
\hline$D^{h i g h} \Delta\left(U_{t}-U_{t}^{*}\right)$ & & $\begin{array}{r}-0.97 \\
(0.35)\end{array}$ & $\begin{array}{r}-0.95 \\
(0.35)\end{array}$ & $\begin{array}{r}-0.89 \\
(0.36)\end{array}$ & $\begin{array}{r}-0.96 \\
(0.35)\end{array}$ & $\begin{array}{r}-0.87 \\
(0.36)\end{array}$ \\
\hline$D_{t}^{\tilde{N}}\left(U_{t}-U_{t}^{*}\right)$ & & & $\begin{array}{r}0.93 \\
(0.55)\end{array}$ & & & $\begin{array}{r}2.32 \\
(0.82)\end{array}$ \\
\hline$D_{t}^{\sim} \Delta\left(U_{t}-U_{t}^{*}\right)$ & & & $\begin{array}{r}0.17 \\
(0.48)\end{array}$ & & & $\begin{array}{r}0.21 \\
(0.50)\end{array}$ \\
\hline$D_{t}^{t>2009}\left(U_{t}-U_{t}^{*}\right)$ & & & & $\begin{array}{r}-0.48 \\
(0.33)\end{array}$ & & $\begin{array}{r}-0.48 \\
(0.36)\end{array}$ \\
\hline$D_{t}^{t>2009} \Delta\left(U_{t}-U_{t}^{*}\right)$ & & & & $\begin{array}{r}-0.45 \\
(0.60)\end{array}$ & & $\begin{array}{r}-0.46 \\
(0.60)\end{array}$ \\
\hline$\left(U_{t}-U_{t}^{*}\right)^{2}$ & & & & & $\begin{array}{r}-0.06 \\
(0.09)\end{array}$ & $\begin{array}{r}0.33 \\
(0.12)\end{array}$ \\
\hline
\end{tabular}

Note: Standard errors (shown in parentheses) are robust for heteroscedasticity and serial correlation. 


\section{Box 1. Background on comparison of health care spending across OECD high-spending countries}

Of the countries examined, the US has by far the highest per-capita total and public health care expenditure and share of GDP spent on health-care (Carey et al., 2009). One feature of the US system that stands out from international comparisons is that the publicly financed share of health care expenditure - though increasing over time - is the lowest of the high-spending countries and covers only a third of the population. Another such feature is that per-capita out-of-pocket (OOP) health care expenditure in the US - although decreasing as a share of expenditure over time-is nonetheless higher than in all other high-spending countries except Switzerland.

The US's higher health care expenditure reported does not appear to be a consequence of the country's higher income, population demographics, or risk factors. Among other things, previous analysis suggests that the higher prevalence of risk factors-such as obesity - in the US explains only a small part of the reported differences in expenditure levels (National Research Council and Institute of Medicine, 2013). In addition, health care quality also does not seem to explain the higher health care expenditure in the US (National Research Council and Institute of Medicine, 2013; Docteur et al., 2009). Comparative measures of performance from the OECD Health Care Quality Indicators show mixed results, with the US system doing well in several areas, such as cancer care, but less well in others, such as in the primary care sector (Organisation for Economic Co-operation and Development, 2015a).

OECD work that compares prices of health care goods and services across countries suggest that prices - as opposed to care volumes (quantity and mix of goods and services consumed) - contribute the most to explaining the higher per-capita expenditure in the US - in line with the conclusions from scholarly work (Anderson et al., 2003; Squires, 2012). Unfortunately, comprehensive health sector price indexes needed to make international comparisons are not widely available (Organisation for Economic Co-operation and Development, 2015b; Koechlin et al., 2014). However, available data for the hospital sector show that the relative price of health care services, reckoned in terms of the overall price level, are substantially higher in the US and Switzerland than in other countries.

Probable explanations for the higher prices of health care goods and services in the US include a more intensive use of costly medical technologies (Smith et al., 2009; Chandra et al., 2011), a larger gap between productivity in the health care sector and other sectors (Hartwig, 2008; Harper et al., 2010; Hocker et al., 2011), the prevalence of decentralised price negotiations (such as for pharmaceuticals), fragmentation in the insurance market (Moriya et al., 2010; Melnick et al., 2011; McKellar et al., 2013), and more intense market concentration in the health care provider industry (White, 2007; Berenson et al., 2012). In addition, systems with multiple payers also tend to be associated with higher prices and less cost control. For instance, apart from Medicare, the US does not have a centralised authority that sets health care expenditure budgets or negotiates prices with providers (White, 2007). Systems with single-payer "public contracts" (Docteur et al., 2004) - such as in Canada, Denmark, France, Germany and Japan-provide greater scope for centralised authorities (either the national government or the social insurance administration) to have leverage over health care providers for price setting, and also seems to have lower administrative costs than multiple-payer systems. 


\section{References}

Anderson G. F., Reinhardt U. E, Hussey P. S., Petrosyan V. (2003). It's the prices, stupid: why the United States is so different from other countries. Health Affairs 22: 89-105.

Anis A, Harvard S and Marra C (2011). Ontario's plunging price-caps on generics: deeper dives may drown some drugs. Open Med 5: e149-52.

Baumol WJ (1967). Macroeconomics of unbalanced growth: The anatomy of urban crisis. American Economic Review, 57(3), 415-426.

Belloni A, Morgan D and Paris V (2016). Pharmaceutical Expenditure and Policies: Past Trends And Future Challenges. OECD Health Working Papers, No. 87, OECD Publishing, Paris. http://dx.doi.org/10.1787/5jm0q1f4cdq7-en

Berenson R. A., Ginsburg P. B., Christianson J. B. and Yee T. (2012). The growing power of some providers to win steep payment increases from insurers suggests policy remedies may be needed. Health Affairs 31: 973-81.

Bradford J. W., Knott D.G., Levine E. H. and Zemmel R. W. (2011). Accounting for the cost of US health care: pre-reform trends and the impact of the recession. Washington, DC: McKinsey Center for US Health System Reform.

Carey, D., B. Herring and P. Lenain (2009), "Health Care Reform in the United States", OECD Economics Department Working Paper, No. 665.

Centers for Medicare and Medicaid Services (2015). National health statistics 2015. http://www.cms.gov/Research-Statistics-Data-and-Systems/Statistics-Trends-and-

Reports/NationalHealthExpendData/

Chandra A. and Skinner J. (2011). Technology growth and expenditure growth in health care. Cambridge: National Bureau of Economic Research.

Congressional Budgetary Office (2016a). The budget and economic outlook 2016-2026.

Congressional Budgetary Office (2016b). Private health insurance premiums and federal policy.

Congressional Budgetary Office (2015). Insurance coverage provisions of the Affordable Care Act CBO's March 2015 Baseline.

Docteur E. and Oxley H. (2004). Health-system reform: lessons from experience. In: Organisation for Economic Co-operation and Development. The OECD health project: towards high-performing health systems. Paris: OECD Publishing. 
Docteur E. and Berenson R. A. (2009). How does the quality of U.S. health care compare internationally? Timely analysis of immediate health policy issues. http://www.urban.org/uploadedpdf/411947_ushealthcare_quality.pdf.

Douven R, Mocking R and Mosca I (2012). The effect of physician fees and density differences on regional variation in hospital treatments (NZa Research Paper, 2012-01). Utrecht: Nederlandse Zorgautoriteit.

Dunn A, Grosse SD and Zuvekas SH (2016). Adjusting Health Expenditures for Inflation: A Review of Measures for Health Services Research in the United States. Health Services Research DOI: $10.1111 / 1475-6773.12612$.

Grady A. (2015). Factors driving Medicaid spending growth. Presentation available at the MacPac website.

Hamada H., Sekimoto M. and Imanaka Y. (2012). Effects of the per diem prospective payment system with DRG-like grouping system (DPC/PDPS) on resource usage and health care quality in Japan. Health Policy 107(2): 194-201.

Harper M. J., Khandrika B., Kinoshita R. and Rosenthal S. (2010). Nonmanufacturing industry contributions to multifactor productivity, 1987-2006. Mon Labor Rev 1: 16-31.

Hartwig J. (2008). What drives health care expenditure?-Baumol's model of 'unbalanced growth' revisited. Journal of Health Economics 27: 603-23.

Health Policy Brief (2016). Medicare's New Physician Payment System. Health Affairs, April 21.

Hoadley J., Cubanski J. and Neuman P. (2015). Medicare's Part D Drug Benefit At 10 Years: Firmly Established But Still Evolving. Health Affairs 34 (10): 1682-7.

Kobayashi Y. (2009). Five Decades of Universal Health Insurance Coverage in Japan: Lessons and future challenges. Japanese Medical Association Journal 52 (4): 263-268.

Koechlin F., Konijn P., Lorenzoni L. and Schreyer P. (2014). Comparing hospital and health prices and volumes internationally. OECD Health Working Papers number 84. Paris: OECD Publishing.

Kumar A. and Schoenstein M. (2013). Managing Hospital Volumes: Germany and Experiences from OECD Countries. OECD Health Working Papers, No. 64. Paris: OECD Publishing.

Law M. R., Ystma A. and Morgan S. G. (2011). The short-term impact of Ontario's generic pricing reforms. PLoS One 6: e23030.

Leu R. E., Rutten F. F. H., Brouwer W., Matter P. and Rutschi C. (2009). The Swiss and Dutch health insurance systems: universal coverage and regulated competitive insurance markets. New York, NY: The Commonwealth Fund.

Lorenzoni L, Belloni A and Sassi F (2014). Health-care expenditure and health policy in the USA versus other high-spending OECD countries. The Lancet 384 (9937): 83-92. 
Martin AB, Hartman M, Washington B, Catlin A and the National Health Expenditure Accounts Team (2017). National Health Spending: Faster Growth in 2015 As Coverage Expands and Utilization Increases. Health Affairs 36 (1).

Martin AB, Hartman M, Benson J, Catlin A and the National Health Expenditure Accounts Team (2016). National Health Spending in 2014: Faster Growth Driven By Coverage Expansion and Prescription Drug Spending. Health Affairs 35 (1): 150-160.

Matsuda R. (2015). The Japanese Health Care System, 2014. In: Mossialos E, Wenzl M (2015). International Profiles Of Health Care Systems 2014. The Commonwealth Fund pub. No. 1802. Pp. 83-91.

McKellar M. R., Naimer S., Landrum M. B., Gibson T. B., Chandra A. and Chernew M. (2013). Insurer market structure and variation in commercial health care spending. Health Services Research. Published online Dec 5. DOI:10.1111/1475-6773.12131.

MedPac (2015). A data book: health care spending and the Medicare program.

Melnick G. A., Shen Y. C. and Wu V. Y. (2011). The increased concentration of health plan markets can benefit consumers through lower hospital prices. Health Affairs 30: 1728-33.

Mladovsky P., Srivastava D., Cylus J., et al. (2012). Health policy responses to the financial crisis in Europe. Policy summary 5. Copenhagen: World Health Organisation Regional Office for Europe and European Observatory on Health Systems and Policies.

Morgan D and Astolfi R (2013). Health spending growth at zero. Which countries, which sectors are more affected? OECD Health Working Papers number 60. Paris: OECD Publishing.

Moriya A. S., Vogt W. B. and Gaynor M. (2010). Hospital prices and market structure in the hospital and insurance industries. Health Economics, Policy and Law 5: 459-79.

National Research Council and Institute of Medicine (2013). U.S. health in international perspective: shorter lives, poorer health. Washington, DC: The National Academies Press.

Nishioka K. (2009). Diagnosis Procedure Combination as a tool for health reform in Japan. Paper presented to the PCSI conference, Fukuoka, Japan.

OECD (2016). OECD Economic Surveys: United States 2016, OECD Publishing, Paris. http://dx.doi.org/10.1787/eco_surveys-usa-2016-en.

OECD (2015b). Fiscal Sustainability of Health Systems: Bridging Health and Finance Perspectives. OECD Publishing, Paris.

OECD (2015a), OECD Economic Outlook, Volume 2015 Issue 2, OECD Publishing, Paris. http://dx.doi.org/10.1787/eco_outlook-v2015-2-en

OECD, Eurostat, WHO (2011). A System of Health Accounts, OECD Publishing.

Paris V., Devaux M. and Wei L. (2010). Health systems institutional characteristics: a survey of 29 OECD countries. OECD Health Working Papers number 50. Paris: OECD Publishing. 
Quentin W, Scheller-Kreinsen D, Blümel M, Geissler A and Busse R (2013). Hospital payment based on diagnosis-related groups differs in Europe and holds lessons for the United States. Health Affairs 32: 713-23.

Rae M, Damico A, Cox C, Claxton G and Levitt L (2015). The Cost of the Individual Mandate Penalty for the Remaining Uninsured. The Henry J Kaiser Family Foundation. Issue Brief, December 2015.

Rosenthal M. B. (2015). Physician Payment after the SGR - The New Meritocracy. The New England Journal of Medicine 373 (13): 1187-9.

Schäfer W., Kroneman M., Boerma W. et al. (2010). The Netherlands: health system review. Health Systems in Transition 12: v-xxvii, 1-228.

Shrank W. H. and Choudhry N. K. (2011). Time to fill the doughnuts-health care reform and Medicare Part D. New England Journal of Medicine 364: 598-601.

Smith J. C. and Medalia C. (2015). Health Insurance Coverage in the United States: 2014. U.S Census Bureau, Current Population Reports, P60-253. Washington, DC.

Smith S., Newhouse J. P. and Freeland M. S. (2009). Income, insurance, and technology: why does health spending outpace economic growth? Health Affairs 28: 1276-84.

Socha K (2014). Mixed reimbursement of hospitals: securing high activity and global expenditure control? Centre of Health economics Research, University of Southern Denmark. Discussion paper 2014: 3 .

Squires D. A. (2012). Explaining high health care spending in the United States: an international comparison of supply, utilisation, prices, and quality. New York, NY: Commonwealth Fund.

Stabile M., Thomson S., Allin S., et al. (2013). Health care cost containment strategies used in four other high-income countries hold lessons for the United States. Health Affairs 32: 643-52.

Sutherland JM (2011). Hospital payment mechanisms: an overview and options for Canada. Ottawa, ON: Canadian Health Services Research Foundation.

The Boards of Trustees, Federal Hospital Insurance and Federal Supplementary Medical Insurance Trust Funds. 2015 annual report. Washington, DC: Boards of Trustees of the Federal Hospital Insurance and Federal Supplementary Medical Insurance Trust Funds.

Thorpe K. and Hockenberry J. (2015). Prescription Drugs And The Slowdown In Health Care Spending. Health Affairs Blog, 18 November.

Vrangbæk K (2015). The Danish Health Care System 2014. In: Mossialos E, Wenzl M (2015). International Profiles Of Health Care Systems 2014. The Commonwealth Fund pub. No. 1802. Pp.33-42.

White C. (2007). Health care spending growth: how different is the United States from the rest of the OECD? Health Affairs 26: 154-61. 
Zhang Y., Donohue J. M., Newhouse J. P. and Lave J. R. (2009). The effects of the coverage gap on drug spending: a closer look at Medicare Part D. Health Affairs 28: w317-25. 